\title{
Atividades Experimentais no Ensino de Física: Diferentes Enfoques, Diferentes Finalidades
}

\author{
Experimentals activities in Physics teaching: Differents approaches, differents objectives \\ Mauro Sérgio Teixeira de Araújo \\ Centro de Ciências Exatas e Tecnológicas, Universidade Cruzeiro do Sul \\ Av. Dr. Ussiel Cirilo, 225 CEP 08060-070, São Paulo, SP \\ e-mail:maurostaraujo@ig.com.br \\ Maria Lúcia Vital dos Santos Abib \\ Faculdade de Educação, Universidade de São Paulo \\ Av. da Universidade, 308 CEP 05508-900 São Paulo-SP \\ e-mail:mlabib@usp.br
}

Recebido em 29 de novembro, 2002. Manuscrito revisado recebido em 16 de abril, 2003; Aceito em 17 de abril, 2003.

\begin{abstract}
Nesse trabalho foi analisada a produção recente na área de investigações sobre a utilização da experimentação como estratégia de ensino de Física, com o objetivo de possibilitar uma melhor compreensão sobre as diferentes possibilidades e tendências dessas atividades tendo em vista subsidiar o trabalho de professores e pesquisadores do ensino no nível médio. A análise dos dados teve como referência os trabalhos publicados entre 1992 e 2001 na Revista Brasileira de Ensino de Física (SBF), em seu encarte Física na Escola e também no Caderno Catarinense de Ensino de Física (UFSC). Foram investigadas a área temática das publicações e diversos aspectos metodológicos relacionados com as propostas de atividades experimentais, como a ênfase matemática empregada, o grau de direcionamento das atividades, o uso de novas tecnologias e a relação com o cotidiano. Os resultados obtidos revelaram que a experimentação continua sendo tema de grande interesse dos pesquisadores, apresentando essa estratégia ampla gama de enfoques e finalidades para o ensino de Física.
\end{abstract}

In this paper were analysed the recent publications about the investigations on experimentation as a strategy of Physics teaching, with the objective of improving the understanding about the different possibilities and tendencies of these activities with an eye to subsidise the teachers and researchers activities at the high school level. The data analysis were based on the articles published between 1992 and 2001 in the Revista Brasileira de Ensino de Física (SBF), in its annex Física na Escola and also in the Caderno Catarinense de Ensino de Física (UFSC). The themes and some methodological aspects related with the proposals of experiments, as the applied mathematical emphasis, the intensity of directivity, the employment of new technologies and the relation to the quotidian were investigated. The results obtained show that the experimentation remain been of great interest of researchers, presenting this strategy a wide range of approaches and objectives to the Physics teaching.

\section{Introdução}

As dificuldades e problemas que afetam o sistema de ensino em geral e particularmente o ensino de Física não são recentes e têm sido diagnosticados há muitos anos, levando diferentes grupos de estudiosos e pesquisadores a refletirem sobre suas causas e conseqüências.

As propostas que têm sido formuladas para o encaminhamento de possíveis soluções indicam a orientação de se desenvolver uma educação voltada para a participação plena dos indivíduos, que devem estar capacitados a compreender os avanços tecnológicos atuais e a atuar de modo fundamentado, consciente e responsável diante de suas possibilidades de interferência nos grupos sociais em que convivem [1].
Nessa direção, o entendimento da natureza da Ciência de um modo geral e da Física em especial constitui um elemento fundamental à formação da cidadania.

De modo convergente a esse âmbito de preocupações, o uso de atividades experimentais como estratégia de ensino de Física tem sido apontado por professores e alunos como uma das maneiras mais frutíferas de se minimizar as dificuldades de se aprender e de se ensinar Física de modo significativo e consistente. Nesse sentido, no campo das investigações nessa área, pesquisadores têm apontado em literatura nacional recente a importância das atividades experimentais [2].

Embora seja praticamente consensual seu potencial para uma aprendizagem significativa, observa-se que a 
experimentação é proposta e discutida na literatura de maneira bastante diversa quanto ao significado que essas atividades podem assumir em diferentes contextos e em diferentes aspectos [3-6]. A análise do papel das atividades experimentais desenvolvida amplamente nas últimas décadas revela que há uma variedade significativa de possibilidades e tendências de uso dessa estratégia de ensino de Física, de modo que essas atividades podem ser concebidas desde situações que focalizam a mera verificação de leis e teorias, até situações que previlegiam as condições para os alunos refletirem e reverem suas idéias a respeito dos fenômenos e conceitos abordados, podendo assim atingir um nível de aprendizado que lhes permita efetuar uma reestruturação de seus modelos explicativos dos fenômenos [7-14].

Assim, apesar da pesquisa sobre essa temática revelar diferentes tendências e modalidades para o uso da experimentação, essa diversidade, ainda pouco analisada e discutida, não se explicita nos materiais de apoio aos professores. Ao contrário do desejável, a maioria dos manuais de apoio ou livros didáticos disponíveis para auxílio do trabalho dos professores consiste ainda de orientações do tipo "livro de receitas", associadas fortemente a uma abordagem tradicional de ensino, restritas a demonstrações fechadas e a laboratórios de verificação e confirmação da teoria previamente definida, o que sem dúvida, está muito distante das propostas atuais para um ensino de Física significativo e consistente com as finalidades do ensino no nível médio.

Desse modo, é possível constatar que o uso da experimentação como estratégia de ensino de Física tem sido alvo de inúmeras pesquisas nos últimos anos, havendo extensa bibliografia em que diferentes autores analisam as vantagens de se incorporar atividades experimentais. Entretanto, a forma e os meios com que a experimentação é empregada difere significativamente nas propostas investigadas, de modo que os trabalhos de diferentes autores apontam para diversas tendências no uso desta estratégia. Nesse sentido, o objetivo principal deste trabalho é identificar algumas das principais características dessas tendências, procurando explicitar seus elementos constitutivos de modo a contribuir para uma melhor compreensão das diferentes formas de utilização da experimentação no ensino médio. Com essa perspectiva, esperamos disponibilizar um quadro com ênfase descritiva que possa subsidiar tanto análises posteriores sobre os diversos enfoques da experimentação presentes na literatura, como também as opções pedagógicas dos professores na organização e planejamento de atividades para a sala de aula.

\section{Metodologia}

Para a elaboração deste trabalho foram selecionados cento e seis artigos publicados na década compreendida entre 1992 e 2001, em dois periódicos de ensino de Física nacionais (Caderno Catarinense de Ensino de Física, publicação quadrimestral editada pela Universidade Federal de Santa Catarina e que teve seu nome modificado recentemente para $\mathrm{Ca}-$ derno Brasileiro de Ensino de Física, e Revista Brasileira de Ensino de Física, publicação trimestral da Sociedade Brasileira de Física, passando parte do conteúdo destinado ao ensino de Física no nível fundamental e médio a ser abordado no encarte semestral denominado Física na Escola a partir do segundo semestre do ano 2000), abordando temas relacionados com o uso da experimentação. A escolha destes dois periódicos deve-se ao fato de permitirem uma análise bastante ampla dos trabalhos que estão sendo desenvolvidos na área de ensino de Física no Brasil, uma vez que são encontrados artigos provenientes de diversos autores e instituições situados em diferentes estados, ao mesmo tempo em que são publicações de fácil acesso e de circulação nacional.

Os trabalhos foram inicialmente analisados e agrupados em categorias em função de sua área temática, o que permitiu a elaboração de um quadro geral do conjunto de artigos. Em uma segunda etapa estes mesmos trabalhos foram analisados procurando-se detectar diferentes aspectos metodológicos relacionados com as atividades experimentais desenvolvidas, sendo cada categoria de análise caracterizada pelos elementos fornecidos resumidamente abaixo:

a) Ênfase Matemática - Analisou-se os trabalhos procurando-se verificar a ênfase matemática adotada na abordagem dos conceitos físicos, ou seja, o nível de matematização e de utilização do formalismo matemático, classificando-se os trabalhos neste momento em Qualitativos e Quantitativos.

b) Grau de Direcionamento - Procurou-se verificar o grau de direcionamento das atividades propostas em função de seu caráter de Demonstração, Verificação ou Investigação e, neste sentido, procurou-se destacar se estas atividades apresentam elementos que as aproximariam mais do ensino tradicional ou se elas apresentariam maior afinidade com métodos investigativos de uma abordagem construtivista.

c) Uso de Novas Tecnologias - Procurou-se detectar o uso de novas tecnologias, com o emprego de computadores e programas específicos para atividades práticas de laboratório ou de simulação.

d) Cotidiano - Nesta categoria foi verificado se o texto dos artigos relacionava os fenômenos físicos abordados com situações típicas encontradas no cotidiano, observando nestes casos se os conceitos estudados poderiam ser utilizados como explicações causais para os fenômenos ligados ao dia a dia.

e) Montagem de Equipamentos - Nesta categoria foram classificados os artigos que procuravam explicitar a montagem de determinados equipamentos, abordando detalhes envolvidos em sua confecção e fornecendo possíveis aplicações para os mesmos.

É importante destacar neste momento que tanto na análise do grau de matematização quanto na análise do grau de direcionamento das atividades foi constatado que, em alguns casos, os trabalhos focalizados nos artigos possuíam elementos de mais de uma categoria, mas a inclusão em uma determinada categoria deu-se em função da identificação de 
seus aspectos predominantes. Por sua vez, a análise realizada nas demais categorias foi feita de maneira independente destas duas primeiras categorias (Ênfase matemática e Grau de direcionamento), de modo que os artigos já incluídos nelas foram novamente reclassificados e devidamente enquadrados nas categoria $\mathrm{c}, \mathrm{d}$ e $\mathrm{c}$ descritas acima.

\section{Análise das publicações segundo a Área de Conhecimento}

Analisando-se o conjunto dos artigos pesquisados segundo a área de conhecimento abordada, foi confeccionada a Tabela I mostrada abaixo, onde os trabalhos foram distribuídos de acordo com o ano de sua publicação.

Tabela I - Área de Conhecimento X Ano de Publicação

\begin{tabular}{|c|c|c|c|c|c|c|c|c|c|c|c|c|}
\hline \hline Área & 1992 & 1993 & 1994 & 1995 & 1996 & 1997 & 1998 & 1999 & 2000 & 2001 & Total & $\%$ \\
\hline Mecânica & 0 & 1 & 3 & 5 & 1 & 2 & 3 & 2 & 2 & 9 & 28 & 30,4 \\
Ótica & 0 & 0 & 3 & 1 & 1 & 1 & 2 & 4 & 3 & 6 & 21 & 22,8 \\
Eletr. Magnetismo & 0 & 4 & 1 & 0 & 0 & 2 & 2 & 5 & 2 & 3 & 19 & 20,7 \\
Física Moderna & 0 & 1 & 0 & 0 & 0 & 0 & 2 & 2 & 0 & 2 & 7 & 7,6 \\
Calorimetria & 0 & 2 & 0 & 1 & 0 & 0 & 1 & 0 & 0 & 0 & 4 & 4,3 \\
Hidrodinâmica & 0 & 0 & 0 & 1 & 1 & 0 & 0 & 1 & 0 & 1 & 4 & 4,3 \\
Gases & 0 & 0 & 1 & 1 & 0 & 0 & 0 & 1 & 0 & 0 & 3 & 3,3 \\
Astronomia & 0 & 0 & 1 & 0 & 1 & 0 & 0 & 1 & 0 & 0 & 3 & 3,3 \\
Ondulatória & 0 & 1 & 0 & 0 & 0 & 0 & 0 & 1 & 1 & 0 & 3 & 3,3 \\
\hline Total & 0 & 9 & 9 & 9 & 4 & 5 & 10 & 17 & 8 & 21 & 92 & 100 \\
\hline \hline
\end{tabular}

Observando esta tabela constata-se um certo predomínio de trabalhos na área de Mecânica, o que pode ser considerado previsível, em virtude da vasta gama de possibilidades de temas que podem ser explorados nesta área e da importância com que esta é normalmente abordada nos cursos do ensino médio. Os trabalhos abordando conceitos de Eletricidade e Magnetismo e Ótica também apresentam destacado número de publicações, de modo que, juntamente com Mecânica, correspondem a aproximadamente $74 \%$ de todos os artigos analisados. Merece destaque ainda o pequeno número de trabalhos sobre conceitos de Física Moderna, pois embora este tema não seja normalmente abordado no ensino médio, o que pode ser justificado em grande parte pelas deficiências formativas dos professores, a sua inclusão nos programas curriculares certamente constituiria uma excelente maneira de possibilitar que os estudantes compreendam diversos fenômenos e situações observadas em seu dia a dia, uma vez que o emprego de equipamentos e tecnologias modernas normalmente foram possibilitados pela aplicação de conhecimentos relacionados com estes tópicos, como efeito fotoelétrico, laser, entre outros.

A Tabela I permite constatar ainda a existência de um conjunto menor de publicações abordando temas como Calorimetria, Gases, Hidrodinâmica, Ondulatória e Astronomia, temas para os quais em grande parte das escolas é destinado um menor tempo do que para o ensino da $\mathrm{Ci}$ nemática, Dinâmica e Eletricidade, que são considerados por muitos professores como conteúdos prioritários. Apesar disto, os diversos trabalhos analisados fornecem um diversificado e rico material para que os conceitos relacionados a estas áreas possam ser explorados experimentalmente, possibilitando assim um maior estímulo para que os estudantes possam compreendê-los.

\section{1 - Publicações relacionadas com a Formação de} Professores e com o Ensino de Laboratório

Além dos 92 artigos classificados segundo a área de conhecimento abordada, verificou-se a existência de um conjunto de 14 artigos cujo foco temático está direcionado para a área de Formação de Professores e para diversos aspectos envolvidos com o Ensino de Laboratório, sendo estes artigos dispostos na Tabela II abaixo.

Tabela II - Artigos sobre Formação de Professores/Ensino de Laboratório X Ano de Publicação

\begin{tabular}{|c|c|c|c|c|c|c|c|c|c|c|c|}
\hline \hline & 1992 & 1993 & 1994 & 1995 & 1996 & 1997 & 1998 & 1999 & 2000 & 2001 & Total \\
\hline For.Prof./Ens.Lab & 4 & 0 & 0 & 1 & 0 & 1 & 0 & 2 & 5 & 1 & 14 \\
\hline \hline
\end{tabular}


Este conjunto de artigos corresponde a $13,2 \%$ do total de 106 artigos analisados, sendo importante destacar que houve um aumento significativo nos últimos anos de publicações sobre Formação de Professores e Ensino de Laboratório, de modo que este crescimento pode indicar que estes temas novamente passaram a ser abordados com maior ênfase pelos pesquisadores, pois aparentemente não tiveram o merecido destaque nos meios acadêmicos ao longo de vários anos, ao menos no que diz respeito à publicações nas fontes pesquisadas neste trabalho. A relevância destes temas pode ser considerada inquestionável na medida em que a mudança de comportamento dos educadores, incorporando novas metodologias de ensino, deveria ser estimulada já em sua fase de formação docente.

\section{Análise das publicações segundo os aspectos metodológicos}

Conforme já apontado anteriormente, o conjunto dos artigos estudados neste trabalho foram analisados em função de quatro categorias não excludentes, visando a explicitação de diferentes ênfases metodológicas associadas aos mesmos, as quais serão analisadas detalhadamente a seguir.

\section{A - Análise da ênfase matemática envolvida nas ati- vidades}

As diferentes modalidades de utilização da experimentação encontradas nos diversos artigos foram analisadas de modo a se detectar a ênfase à matematização envolvida na atividade proposta [15]. Nesse sentido, procurou-se verificar se as atividades experimentais eram propostas objetivando salientar aspectos formais relacionados com teorias e modelos matemáticos, com eventuais previsões e verificações dos mesmos, ou se, de outra forma, eram os aspectos qualitativos, metodológicos, conceituais e fenomenológicos que predominavam na abordagem em questão. Desta forma, os trabalhos foram agrupados em duas categorias distintas: Qualitativos e Quantitativos.

\section{A.1 - Qualitativos}

A parcela majoritária dos artigos analisados, correspondendo a dois terços do total, foi enquadrada nesta categoria, constatando-se que enfatizavam aspectos qualitativos, metodológicos e conceituais relacionados com o tema abordado, seja envolvendo o uso de laboratórios não estruturados [16], experimentos qualitativos $[17,18]$ ou mesmo enfocando atividades práticas de demonstração [19-23] ou de investigação $[4,24]$, desenvolvidas através de procedimentos nos quais os aspectos formais e quantitativos não eram enfocados ou apareciam apenas em segundo plano. Estas abordagens qualitativas podem estar relacionadas com aspectos do cotidiano [24], com o uso de computadores [25-27], com a formação de professores e estudos relacionados ao uso de laboratórios didáticos [1,5,28,29], com a construção de equipamentos
[30, 31], e ainda com aspectos gerais da divulgação científica em ambiente escolar [32].

No que diz respeito à utilização de laboratórios não estruturados e ao uso de experimentos qualitativos, podese afirmar que se trata de duas modalidades típicas de experimentação nas quais os aspectos qualitativos relacionados com os fenômenos e conceitos abordados nas atividades sobressaem-se sobre os aspectos quantitativos. Deste modo, comparando-se estas duas modalidades com as atividades realizadas em laboratórios estruturados é fácil constatar que há diferenças significativas tanto em relação aos objetivos pretendidos quanto em relação aos aspectos a serem salientados no desenvolvimento das atividades práticas. Estas diferenças podem ser justificadas na medida em que, em geral, as atividades com LNE permitem uma abordagem que privilegia os aspectos qualitativos envolvidos no processo, com destaque para os aspectos de natureza conceitual, que podem ser relacionados com a verificação de conceitos espontâneos, teste de hipóteses e mudança conceitual $[16,33,34]$, empregando uma metodologia que possibilita aos alunos buscarem por si mesmos as respostas e soluções para os problemas apresentados [4]. Considerando-se as possíveis diferenças metodológicas de utilização do LNE, pode-se afirmar ainda que estas atividades podem ser desenvolvidas baseadas na utilização de questões problematizadoras [35] ou através de situações que possibilitem verificar a adequação ou não do modelo não estruturado diante de eventuais deficiências formativas dos alunos [36].

Por sua vez, a utilização de experimentos qualitativos, propostos por Alberto Villani [17,18], também tem por objetivo destacar os aspectos qualitativos relacionados com as atividades experimentais, procurando-se verificar através das mesmas a existência de conceitos espontâneos nos alunos e a possibilidade de ocorrência de mudanças conceituais produzidas pela criação de condições que facilitem o processo de reflexão, em uma abordagem com enfoque com características cognitivistas [37].

\section{A.1.1 - Comentários e considerações}

Além dos artigos citados, há ainda outros trabalhos que também centram atenção nos aspectos qualitativos vinculados ao tema abordado, principalmente quando relacionados com experimentos de demonstração e construção de equipamentos [38,39], formação de professores e pesquisas sobre eventuais melhorias de ensino decorrentes do uso de laboratórios [35,40-42] e, em alguns casos, com atividades de investigação através das quais os aspectos conceituais e fenomenológicos se sobressaem em relação aos aspectos formais e quantitativos [16,33,34]. Vários destes trabalhos, que podem abordar tanto tópicos de Física Moderna [43,44] quanto de Física Clássica [45,46], serão abordados mais profundamente nos tópicos B.1 e B.3, destinados especificamente à análise das atividades de demonstração e de investigação. 


\section{A.2 - Quantitativos}

A utilização de experimentos enfatizando os aspectos quantitativos constitui uma modalidade empregada com bastante freqüência, correspondendo a um terço dos artigos publicados nas fontes pesquisadas. Nesse tipo de abordagem podem ser atingidos diferentes objetivos, com destaque para a possibilidade de se comparar os resultados obtidos com os valores previstos por modelos teóricos [4752]. A verificação de leis físicas e de seus limites de validade também são objetivos alcançados através do uso da experimentação quantitativa [53,54].

Outro aspecto importante relacionado com atividades experimentais quantitativas é a possibilidade de se introduzir conceitos relativos ao tratamento estatístico de dados, fornecendo-se noções sobre procedimentos que devem ser adotados na etapa de medições, o uso adequado de diferentes instrumentos de medida, bem como a existência de erros estatísticos e sistemáticos nessas medidas [55-57]. Nesta linha de trabalho, o artigo de Laburú [58] aborda a construção e utilização de dois equipamentos, salientando aspectos como a precisão das medidas e dos instrumentos, comparando-se os resultados com os obtidos através de instrumentos mais simples, enquanto o trabalho de Amaku [55] discute a necessidade de um adequado cálculo de incertezas na determinação da dimensão fractal de pães amassados. Embora considerado como um objetivo secundário, as questões relativas à análise das incertezas presentes no processo de medição também são abordadas no trabalho de Chernikoff [53].

Além dos objetivos já mencionados, alguns autores salientam que a utilização da experimentação quantitativa permite tornar mais concretos os conceitos abordados [56], possibilitando ainda a realização de atividades interdisciplinares [6, 59]. Cabe ainda destacar que em virtude de suas características, a experimentação com ênfase nos aspectos quantitativos também permite estimular a criatividade e uma relação mais próxima entre professores e os alunos [47], fato que pode tornar as aulas mais interessantes e gerar grande entusiasmo e participação nos alunos $[6,56]$, proporcionando maior estímulo e interesse pelo estudo dos conteúdos de Física que são abordados [60].

Para destacar algumas diferenças metodológicas e de procedimentos relacionados com as atividades experimentais quantitativas, serão fornecidos a seguir alguns exemplos de propostas de atividades interessantes, como a abordagem experimental não usual empregada no artigo de Simões Filho [61], onde os dados referentes ao estudo experimental do movimento de um carro de corrida de fórmula 1 são obtidos a partir das imagens fornecidas pela televisão, onde são mostradas as velocidades do carro ao longo do percurso realizado. Deste modo, são construídos gráficos de velocidade e aceleração que permitem estimar a potência do automóvel, bem como analisar-se os efeitos do atrito sobre os mesmos.

Medidas do ângulo de reflexão e da distância focal de lentes são alguns dos resultados que podem ser obtidos com a utilização de apontadores laser em atividades quantitativas na área de ótica $[39,62]$, merecendo destaque a proposta de medição do diâmetro de um fio de cabelo através da difração por obstáculo utilizando um apontador laser [57].

O estudo experimental da lei dos gases ideais realizado por Bagnato e colaboradores [63] procura fornecer aos alunos subsídios para a compreensão de diversos fenômenos observados no dia a dia, uma vez que permite estabelecer uma relação de proporcionalidade entre o volume ocupado por um gás e a sua temperatura (Lei de Gay-Lussac), em uma situação onde a pressão é mantida constante.

A construção de um calorímetro de baixo custo, como alternativa aos adquiridos comercialmente, permite obter medidas relativamente precisas dos parâmetros envolvidos nos processos de equilíbrio térmico, apresentando como vantagem um melhor isolamento térmico e maior facilidade de manuseio [64].

Muitos fenômenos físicos estão relacionados com eventos que envolvem partículas em escala microscópica ou situações que não permitem uma fácil observação direta. Nestes casos é possível elaborar experimentos capazes de simular este tipo de fenômeno e, desta forma, possibilitar a verificação de algumas previsões fornecidas por modelos teóricos. Nesta abordagem de experimentação quantitativa pode ser citado o estudo da condutividade mecânica como análogo para a condutividade elétrica, interpretada segundo o modelo de Drude [65]. Nesse trabalho é feita a montagem de uma tábua inclinada com pregos que funcionam como centros espalhadores de bolinhas de gude soltas do topo, medindo-se então o tempo gasto para atingir a base do plano e construindo-se gráficos que permitem obter o valor da condutividade mecânica do sistema e, desse modo, avaliar a validade do modelo utilizado. Também nessa linha de trabalho, o artigo de Cavalcante e colaboradores [59] aborda a descoberta do núcleo através de um experimento que simula o espalhamento de partículas observado na experiência de Rutherford.

Fenômenos relacionados com a Física Moderna também podem ser abordados quantitativamente, possibilitando compreender aspectos vinculados com a estrutura e os modelos atômicos [59,66-68]. Por sua vez, a utilização de computadores nos processos de aquisição e análise de dados permite a criação de um ambiente de investigação científica e o domínio e aplicação de novas tecnologias [25,69-72], embora seja necessário realizar-se uma adequada capacitação dos professores envolvidos [73].

\section{A.2.1 - Comentários e considerações}

Deve-se ressaltar que atividades experimentais quantitativas permitem fornecer conhecimentos inerentes a alguns procedimentos típicos da investigação científica, como utilização adequada de equipamentos e instrumentos de medida, análise e tratamento estatístico de dados, cuidados com erros sistemáticos, entre outros.

Por outro lado, é importante salientar que apesar de permitirem uma participação mais ativa dos alunos, a maioria das atividades experimentais quantitativas tendem a ser utilizadas por meio de procedimentos e roteiros fechados 
que permitem classificar este tipo de atividade experimental como verificacionista, de modo que em geral não são enfatizados importantes elementos, como a existência de conceitos espontâneos nos alunos e o incentivo a momentos de reflexão e aprofundamento de discussões acerca dos conteúdos, o que poderia ocasionar uma maior eficiência no processo de aprendizagem. Neste sentido, é comum em atividades desta natureza observar-se uma certa limitação na manifestação da criatividade dos alunos, uma vez que o propósito de verificar a validade de determinadas previsões teóricas ocorre em geral por meio de roteiros previamente estabelecidos.

Portanto, as atividades experimentais quantitativas podem ser enriquecidas adotando-se uma postura mais flexível, que possibilite a introdução de outros elementos e métodos, como discussões que propiciem reflexões críticas acerca dos fenômenos estudados e da estrutura de funcionamento dos equipamentos utilizados, bem como dos elementos e fatores que influenciam o experimento e que podem acarretar eventuais discrepâncias entre os resultados observados experimentalmente e as previsões teóricas que se pretendia verificar. Um exemplo nesse sentido pode ser considerado o trabalho de Chernikoff e colaboradores [53], que utilizando equipamentos de baixo custo e fácil aquisição realizam estudos quantitativos que permitem verificar a lei de Boyle e estudar algumas propriedades dos gases empregando um arranjo experimental que propicia fácil manuseio pelos alunos, que podem assim formular e verificar hipóteses acerca do seu funcionamento. Acredita-se que este tipo de comportamento por parte de quem conduz as atividades práticas pode contribuir efetivamente para um aprendizado mais significativo dos conceitos físicos analisados.

\section{B - Análise do grau de direcionamento das atividades}

$\mathrm{Na}$ análise dos artigos também procurou-se verificar o grau de direcionamento das atividades, destacando-se se as atividades apresentam um caráter de Demonstração, Verificação ou Investigação, bem como salientar se estas práticas apresentam elementos que as aproximariam do ensino tradicional ou se elas estariam baseadas em métodos investigativos típicos de uma abordagem construtivista.

\section{B.1 - Atividades de Demonstração/Observação}

Uma das modalidades da experimentação mais utilizadas pelos autores investigados refere-se ao emprego de atividades de demonstração. Provavelmente, a característica mais marcante dessas atividades é a possibilidade de ilustrar alguns aspectos dos fenômenos físicos abordados, tornando-os de alguma forma perceptíveis e com possibilidade de propiciar aos estudantes a elaboração de representações concretas referenciadas. Entretanto, através da análise das atividades propostas constata-se que elas tendem a ser desenvolvidas através de dois procedimentos metodológicos bastante distintos, que podem ser denominados de Demonstrações Fechadas e Demonstrações/Observações Abertas. Nesse sentido, enquanto as demonstrações fechadas se caracterizam principalmente pela simples ilustração de um determinado fenômeno físico, sendo uma atividade centrada no professor que a realizada, as atividades de demonstração/observação aberta incorporam outros elementos, apresentando uma maior abertura e flexibilidade para discussões que podem permitir um aprofundamento nos aspectos conceituais e práticos relacionados com os equipamentos, a possibilidade de se levantar hipóteses e o incentivo à reflexão crítica, de modo que a demonstração consistiria em um ponto de partida para a discussão sobre os fenômenos abordados, com possibilidade de exploração mais profunda do tema estudado. Desse modo, por apresentar diversas características inerentes às atividades investigativas, julgou-se mais adequado inserir as atividades de demonstração/observação abertas na categoria de investigação que será discutida posteriormente no item B.3.

Assim, na linha de proposta de atividades de demonstração encontram-se autores que salientam justamente a importância dessas atividades para ilustrar e tornar menos abstratos os conceitos físicos abordados, ao mesmo tempo que torna mais interessante, fácil e agradável o seu aprendizado, motivando a participação dos alunos [74-80]. A compreensão de um fenômeno através de uma demonstração pode permitir aos alunos compreenderem o funcionamento de outros equipamentos e generalizar o comportamento dos sistemas observados para outras situações em que estes mesmos fenômenos estejam presentes [81, 82].

Alguns exemplos mais significativos e interessantes de trabalhos relacionados aos uso de atividades de demonstração serão fornecidos a seguir, destacando-se inicialmente a possibilidade de se abordar fenômenos eletromagnéticos [83], alguns normalmente de difícil compreensão [84], utilizando-se procedimentos capazes de fornecer resultados bastante convincentes para os alunos [85] e contribuindo para aumentar a sua motivação [20]. Nessa área de eletromagnetismo, verifica-se que as atividades de demonstração podem ser empregadas como meio de se ilustrar o surgimento de uma força eletromotriz (fem) produzida pelo movimento de um objeto condutor imerso em um campo magnético [86], acreditando-se que através deste procedimento é possível tornar a compreensão dos fenômenos de indução eletromagnética mais completa.

Artigos bastante curtos e objetivos são encontrados na Revista Física na Escola, abordando tópicos de mecânica [21] e de hidrostática [87]. Nessa revista encontra-se ainda um interessante artigo que aborda o uso de diversas atividades de demonstração como estratégia de divulgação científica [32].

O uso de atividades de demonstração também é defendido no processo de formação docente, de modo a preparar os professores para uma prática docente segura e eficiente [88], capaz de efetuar uma distinção entre a Física e a Matemática e enfatizar os aspectos conceituais envolvidos. Assim, a formação dos professores deve englobar o projeto e o uso de materiais de demonstração, capacitando-os a contornar os problemas de falta de recursos e principalmente eliminar o despreparo verificado entre professores para o uso de 
atividades experimentais, sendo esta proposta também defendida por outros autores [35].

$\mathrm{O}$ aspecto do desafio colocado para o estudante relacionado à explicação de um fenômeno observado em uma demonstração, que pode até mesmo violar o senso comum, também consiste de uma metodologia utilizada [89], estimulando que o estudante reproduz a atividade e, assim, encontre maior facilidade no entendimento do seu funcionamento [90].

A abordagem dos aspectos históricos relacionados ao tema estudado é uma metodologia defendida por diversos autores, podendo-se destacar no contexto das atividades de demonstração a tentativa de resgatar alguns aspectos históricos do experimento de Thomas Young encontrada no trabalho de Braun [91], que enfoca os conceitos de interferência, difração e coerência luminosa, procurando propiciar uma exploração didática dos conceitos de óptica e facilitar a compreensão dos mesmos. Neste mesmo sentido, o artigo de Galli e Salami [92] propõe o estudo dos fenômenos de interferência e difração da luz através do registro de figuras de difração em papel fotográfico, defendendo a idéia de que através destas atividades de demonstração é possível motivar os alunos, esclarecer alguns aspectos relacionados com os fenômenos abordados, bem como efetuar uma abordagem histórica sobre a proposta de se considerar a natureza ondulatória da luz. Ainda utilizando aspectos históricos como pano de fundo, há um artigo que descreve a construção e o funcionamento da fonte de Heron, antigo matemático de Alexandria, empregando garrafas plásticas de refrigerante [93], enquanto um trabalho mais recente aborda o experimento de Michelson e Morley e a sua relação com a Teoria da Relatividade de Einstein utilizando um interferômetro de baixo custo [19]. Nesta mesma linha de abordagem histórica, verifica-se um outro trabalho que descreve a construção e funcionamento de um modelo da máquina termo-pneumática de Hero, utilizada para abrir e fechar as portas dos antigos templos [94].

Por sua vez, na área de óptica, existem propostas de construção e utilização de um dispositivo que permite compreender o funcionamento da estrutura do olho humano no processo de focalização das imagens e a correção de problemas da visão [21, 38]. Uma proposta alternativa para auxiliar o entendimento do funcionamento do olho humano é encontrada no artigo de Saba [23], que descreve a dissecação de um olho de boi. A descrição da construção e utilização de uma luneta astronômica utilizando materiais de fácil aquisição pode ser um procedimento de grande importância para os professores do ensino básico, na medida em que estes poderão empregá-la em sala de aula, motivando a participação dos alunos e promovendo uma maior facilidade de aprendizado dos conceitos abordados [95]. Em trabalhos posteriores, o mesmo autor propõe diversas utilidades para um cone duplo em aulas de demonstração [89] e o emprego de bolas de isopor para ensinar conceitos básicos de Astronomia de maneira realista e motivadora para os alunos [77].

Diversos conceitos de Física Moderna e Contemporânea também podem ser abordados através de atividades de demonstração, como laser e efeito fotoelétrico [44], hologramas [96] e ondas eletromagnéticas estacionárias em cavidades de fornos de microondas [97], possibilitando-se o aprendizado de diversos conceitos envolvidos com os equipamentos e dispositivos tecnológicos cada vez mais presentes no cotidiano.

A utilização de computadores como ferramenta auxiliar em atividades de demonstração também é proposta, destacando-se a possibilidade de facilitar a compreensão dos fenômenos físicos estudados [27].

\section{B.1.1 - Comentários e considerações}

Dentre os diversos aspectos que merecem ser salientados, destaca-se o fato das atividades de demonstração possibilitarem ilustrar um determinado fenômeno, podendo contribuir para a compreensão de diversos aspectos relacionados ao mesmo. Em geral, tais atividades demandam um pequeno tempo de realização e podem ser facilmente integradas a uma aula com ênfase expositiva, sendo utilizadas como um fechamento da aula ou como seu ponto de partida, procurando despertar o interesse do aluno para o tema que será abordado. Para que seja ampliada a eficiência do processo de aprendizagem, acredita-se que estas atividades devam ser conduzidas de modo que seja permitido o questionamento por parte dos alunos, incentivando-os a buscar explicações para os fenômenos estudados, possibilitando assim a elaboração de novas idéias a partir da vivência de situações capazes de propiciar o desenvolvimento de sua capacidade de abstração e de aprendizagem [37, 45].

Portanto, a análise dos trabalhos que abordam o uso de demonstrações permite constatar que, embora elas geralmente sejam conduzidas inicialmente pelos professores, dependendo do caso, os alunos devem em seguida repetir os procedimentos. Neste sentido, em que pese as limitações de toda atividade de demonstração, uma vez que essas situações em geral são fechadas e definidas pelo que se quer mostrar, na maioria das vezes impossibilitando variações por parte dos estudantes, é fundamental que essa atividade propicie condiç ões para que haja reflexão e análise dos mesmos. Esta atitude deve ser incentivada pelos professores, seja pela formulação de questões ou através da permissão para que os estudantes interfiram e alterem os arranjos experimentais propostos, dando oportunidade para que eles formulem hipóteses, analisem as variáveis intervenientes e discutam criticamente os possíveis modelos explicativos dos fenômenos observados [98].

Enfim, utilizando metodologias que permitam explorar ao máximo cada atividade de demonstração é possível fazer com que estas superem a simples ilustração de um fenômeno e possam contribuir efetivamente para o aprendizado conceitual desejado e para o desenvolvimento de novas habilidades e posturas dos estudantes. Procedimentos desta natureza, concomitantes com relatos de melhorias no nível de aprendizado observado em estudantes a partir do uso de aulas demonstrativas [40], reforçam a crença de que estas atividades 
podem de fato contribuir para melhorar a qualidade do ensino de Física.

\section{B.2 - Atividades de Verificação}

As atividades de verificação são caracterizadas por uma maneira de se conduzir a atividade experimental na qual se busca a verificação da validade de alguma lei física, ou mesmo de seus limites de validade. A importância destas atividades pode ser destacada, entre outros fatores, pela sua capacidade de facilitar a interpretação dos parâmetros que determinam o comportamento dos sistemas físicos estudados, sendo, segundo alguns autores, um recurso valioso para tornar o ensino estimulante e a aprendizagem significativa, promovendo uma maior participação dos alunos [49, 89, 99, 100]. Outro aspecto relevante é a possibilidade destas atividades promoverem o desenvolvimento da capacidade de se efetuar generalizações [82], que pode ocorrer quando são extrapolados os limites do experimento de modo a explorar novas situações [47]. Ao mesmo tempo que serve para motivar os alunos, as atividades de verificação podem contribuir para tornar o ensino mais realista, no sentido de se evitar alguns erros conceituais observados em livros-texto [101].

Entre alguns exemplos relevantes de propostas de atividades de verificação pode-se destacar a utilização de um CD e um retroprojetor para construir espectroscópios de baixo custo que permitem obter espectros de difração bastante nítidos, possibilitando efetuar-se cálculos aproximados da constante de rede do CD [66]. Também empregando um CD como rede de difração, o trabalho de Cavalcante e colaboradores [43] utiliza uma caneta laser como fonte de radiação incidente para verificar o número de sulcos por milímetro presentes no CD. Modificações no arranjo experimental possibilitam que também sejam abordados aspectos relacionados com erros em medidas físicas, tema bastante importante e que afeta toda atividade experimental quantitativa.

Em outro artigo, com proposta semelhante, também é utilizado um CD como rede de difração de um espectroscópio, sendo este empregado para verificar as diferenças entre os espectros produzidos por lâmpadas de Neônio, Argônio e Sódio e comparar com o espectro contínuo de uma lâmpada incandescente, podendo-se, deste modo, abordar alguns aspectos relacionados com os modelos atômicos [68]. Ainda abordando o fenômeno de difração, observa-se uma proposta alternativa de produção de redes de difração através de fotografias de matrizes periódicas [30], enquanto o trabalho de Lopes e Laburú [57] utilizam a difração em uma proposta interessante e motivadora para os alunos, na medida em que procuram medir a espessura de fios de cabelo por meio de difração por obstáculo.

Também na área de fenômenos óticos, encontra-se uma proposta de estudo da refração da luz em lentes esféricas, procurando-se verificar as predições da equação das lentes para sistemas que apresentam índice de refração $n \neq 1 \mathrm{e}$, deste modo, facilitar o entendimento de como funcionam estas lentes [79].

Complementando o trabalho de Dornelles Filho [49], o artigo de Canalle [101] verifica o comportamento de um sis- tema hidrostático, apontando para a presença de um erro nos livros de ensino fundamental e mostrando como alguns professores contornam o problema de maneira indevida.

Trabalhando com sistemas mecânicos alternativos à mola de aço para verificar a lei de Hooke encontra-se um artigo com proposta de utilização de materiais de baixo custo, como réguas e espirais de plástico de encadernação, que fornecem resultados bastante satisfatórios em relação aos equipamentos comerciais [54]. Este mesmo autor propõe em um outro artigo a construção de um dispositivo mecânico para medir a freqüência da rede elétrica baseando-se no efeito estroboscópio proveniente da intermitência de lâmpadas fluorescentes, de modo que os resultados ilustrados permitem verificar de maneira bastante satisfatória que a freqüência de oscilação da rede é próxima de $60 \mathrm{~Hz}$ [60].

$\mathrm{Na}$ área de mecânica há uma proposta de se estudar as condições de equilíbrio de vários sistemas através de um conjunto de polias e massas padronizadas, comparando-se os resultados experimentais com os previstos pelos modelos teóricos [47]. Nesta mesma área, constata-se a existência de um trabalho que analisa o comportamento de um esfera atuando como um corpo rígido que se desloca em um plano inclinado, comparando-se os resultados com os obtidos quando se considera a esfera como um objeto pontual [50]. Medidas do momento de inércia de um disco girante [52] e do centro de massa de um sistema [48] são outros procedimentos propostos que permitem comparar os resultados com previsões dos modelos teóricos.

Analisando dados obtidos a partir de imagens de televisão, o artigo de Simões Filho [61] realiza um estudo quantitativo através de gráficos de velocidade e aceleração do movi-mento de um carro de fórmula 1, estimando assim a sua potência e os efeitos do atrito.

Utilizando um sistema mecânico simples, Bagnato [65] propõe uma forma de se verificar a lei de Ohm a partir do comportamento da condutividade mecânica do sistema, proposta como analogia para o estudo da condutividade elétrica de um sólido condutor decorrente da presença de centros espalhadores observada no modelo de Drude. Através de um arranjo experimental bastante criativo, envolvendo um balão de borracha submerso, o mesmo autor sugere uma forma alternativa de se verificar experimentalmente a lei dos gases, possibilitando que os alunos possam explicar várias situações encontradas no dia a dia [63]. Em área correlata, empregando equipamentos de baixo custo observa-se uma proposta para verificar quantitativamente a lei de Boyle, utilizando-se um arranjo experimental que permite um fácil manuseio por parte dos alunos [53].

Propondo um procedimento bastante interativo para o aprendizado de alguns conceitos de astronomia, encontrase um artigo que utiliza um gnômon em um Jardim Astronômico para obter a altura do Sol, o meio-dia solar, os pontos cardeais e as estações do ano para qualquer latitude [102].

Por sua vez, através da proposta de utilização de um calorímetro com gelo observa-se que é possível determinar a constante solar, verificando-se uma satisfatória proximidade 
entre o valor obtido experimentalmente e o fornecido na literatura [51].

Por fim, foram analisados trabalhos que utilizam computadores para aquisição e análise de dados, sendo empregados no estudo das oscilações de um pêndulo físico [71], no estudo das características de um circuito RC serial [72] e em um arranjo que permite estudar a influência da altura e da velocidade inicial no alcance de uma esfera metálica lançada horizontalmente [103], salientando-se que o uso do computador permite aos alunos dedicar maior tempo na interpretação dos resultados e, consequentemente, possibilitando um melhor aprendizado dos conteúdos de Física.

\section{B.2.1 - Comentários e considerações}

Através do conjunto de artigos analisados verifica-se que são amplas as possibilidades de utilização de atividades experimentais que visam a verificação de leis físicas e o estudo do comportamento de diferentes sistemas físicos. Ainda que estas atividades apresentem limitações inerentes à sua própria característica, acredita-se que quando conduzidas adequadamente elas também podem contribuir para um aprendizado significativo, propiciando o desenvolvimento de importantes habilidades nos estudantes, como a capacidade de reflexão, de efetuar generalizações e de realização de atividades em equipe, bem como o aprendizado de alguns aspectos envolvidos com o tratamento estatístico de dados e a possibilidade de questionamento dos limites de validade dos modelos físicos. Portanto, a adequada condução das atividades pode ser considerada novamente como um elemento indispensável e fundamental para que seja alargado o leque de objetivos e o desenvolvimento de posturas e habilidades que podem ser promovidos através de atividades dessa natureza.

\section{B.3 - Atividades de Investigação}

Em tópico anterior foram analisados alguns aspectos qualitativos relacionados com a utilização de laboratórios não estruturados (LNE). Enfocando neste momento a sua utilização como uma atividade com caráter de investigação constata-se a existência de outros elementos que ampliam a sua diferenciação em relação ao laboratório estruturado, uma vez que este freqüentemente faz uso de roteiros fechados, com menores possibilidades de intervenção e/ou modificações por parte dos alunos ao longo das etapas do procedimento experimental. Entretanto, segundo Ribeiro [36], as deficiências formativas observadas nos alunos poderiam implicar na necessidade de uso da experimentação baseada em um modelo estruturado nas etapas iniciais, enquanto em uma etapa posterior, quando os alunos já estariam familiarizados com o laboratório, poderiam ser utilizadas abordagens não estruturadas.

Outros autores, por sua vez, defendem o emprego do laboratório não estruturado como meio de investigação e/ou resolução de problemas, que pode possibilitar aos alunos o teste de hipóteses, propiciando o desenvolvimento da capacidade de observação, de descrição de fenômenos e até mesmo de reelaboração de explicações causais, aspectos que contribuiriam para facilitar a reflexão e, consequentemente, o progresso intelectual dos estudantes [11,17,24,33,34]. Nessas situações, conforme salienta Gonçalves [34], a participação dos professores é fundamental para auxiliar e estimular os alunos na busca das explicações causais, através das quais alcança-se um novo patamar no aprendizado dos conceitos abordados.

Cabe ainda salientar que as atividades experimentais que tomam por base propostas de LNE podem exigir dos estudantes um tempo maior de estudo, uma vez que as etapas de execução, análise e conclusões demandam um grande envolvimento, propiciando assim um melhor entendimento dos fenômenos físicos estudados [17]. Nesse sentido, Castro e Cerqueira [35] destacam que o uso de materiais concretos pode ser capaz de suscitar questões problematizadoras que podem desencadear uma nova prática de ensino com o despertar do interesse dos estudantes. Salientam ainda que a eficiência dessa abordagem depende em grande parte do envolvimento dos estudantes no processo de aprendizagem, o que converge para o posicionamento de Ventura [7] que, além desses aspectos, ressalta a importância de um preparo adequado do professor. Com esse direcionamento, investigando deficiências formativas existente entre professores, Figueroa e Gutierrez [88] propõem a utilização de demonstrações como um elemento motivador na formação dos professores, capacitando-os a ter maior segurança e confiança no desenvolvimento de suas atividades docentes. Em trabalhos mais recentes também são enfocadas questões relativas à necessidade de se oferecer uma melhor formação aos professores das áreas científicas, de modo que as atividades experimentais devam ser exploradas a partir de um novo enfoque [1], questionando-se ainda a necessidade de atualização dos currículos de Física no sentido de incluírem tópicos de Física Moderna e Contemporânea, tomando-se os devidos cuidados na preparação dos professores para que possam abordar esses temas adequadamente [28]. Nessa questão de currículo, Cavalcante e Nakamura [59] destacam que a abordagem de temas de Física Moderna de uma maneira interdisciplinar e utilizando recursos computacionais seria uma forma de se atualizar os currículos de Física no ensino médio.

Segundo Barbosa [16], empregando-se a experimentação com LNE verifica-se que há uma maior eficiência quanto à ocorrência de mudança conceitual nos estudantes e, consequentemente, maior facilidade de aprendizagem de conceitos científicos quando se utiliza um ensino experimental baseado em uma abordagem que explora este tipo de atividade em comparação com o ensino tradicional.

Em direção convergente, o uso de experimentos qualitativos é proposto como forma de se investigar as relações entre conceitos espontâneos e experimentos simples, sendo esta modalidade defendida por possibilitar, em alguns casos, condições para a reflexão e o crescimento intelectual dos estudantes no sentido de ampliar o seu conhecimento científico em decorrência de mudança conceitual [17]. O 
mesmo autor, em trabalho posterior baseado em entrevistas [18], analisa as dificuldades observadas em estudantes submetidos a atividades experimentais qualitativas simples. Nesse trabalho, é sugerida uma abordagem dos conceitos científicos a partir da criação de situações capazes de gerar elementos concretos que servirão de base para um diálogo que favoreça a mudança conceitual desejada. Essas mudanças conceituais podem ser alcançadas por alunos submetidos a atividades com enfoque construtivista, realizadas através de experimentos qualitativos baseados em sequiências de ensino que envolvem uma problematização inicial, a montagem e execução do experimento, uma organização dos conhecimentos adquiridos e, finalmente, a aplicação destes conhecimentos a outras situações diferentes das que foram propostas inicialmente [16]. Entretanto, apesar de se verificar condições mais propícias para a ocorrência de rupturas no entendimento conceitual dos estudantes através de atividades investigativas, observa-se em algumas situaç ões que há uma tendência em se preservar elementos dos modelos interpretativos anteriores à estas atividades [13].

Por outro lado, conforme mencionado anteriormente, as atividades de demonstração abertas também podem ser consideradas como uma modalidade de atividade de investigação, desde que a condução dessas atividades permita a participação dos estudantes, manipulando os equipamentos, questionando e elaborando hipóteses, devendo estes procedimentos ser estimulados para que o aprendizado seja mais eficiente $[46,104]$. Adotando esta metodologia, o artigo de Moura e Canalle [105] propõe a quebra de um imã em sala de aula como elemento motivador para que os estudantes possam observar e analisar os fenômenos magnéticos, procurando elaborar explicações e checando a validade das mesmas através da manipulação do experimento. Através deste procedimento evidencia-se a possibilidade de se explorar as atividades de demonstração superando a simples ilustração de um determinado fenômeno $\mathrm{e}$, assim, auxiliar o desenvolvimento de habilidades inerentes ao espírito científico. Nesse sentido, a possibilidade de discussão e de ocorrência de debates críticos sobre as observações dos fenômenos demonstrados é um aspecto relevante destacado por Laburú [106] acerca das atividades de demonstração, que podem permitir uma abordagem quantitativa complementar. Também nesta linha, o trabalho de Axt [107] utiliza uma metodologia baseada no desafio ao estudante para explicar um determinado fenômeno observado em uma atividade de demonstração inicial que contraria o senso comum.

Entre outros exemplos de propostas de atividades de investigação que podem ser destacados do conjunto de artigos analisados, constata-se a possibilidade de introdução de noções relacionadas a medições e erros de medida verificada no trabalho de Oliveira e colaboradores [56], que sugerem um processo de investigação baseado na realização de medidas do tempo de reação dos alunos. O processo investigativo também pode ser empregado para demonstrar o funcionamento de equipamentos como displays de relógios e calcu- ladoras, elucidando aspectos relacionados com a aplicação tecnológica de conceitos de Física Contemporânea que aparecem no cotidiano [108]. Este processo pode ser auxiliado pela utilização de computadores, permitindo assim uma eficiente coleta e análise de dados, em um ambiente criativo e que possibilite o desenvolvimento da capacidade crítica dos estudantes $[109,110]$. Além desses fatores, o uso de ferramentas computacionais pode auxiliar o processo de reestruturação conceitual ao permitir a reflexão por parte dos estudantes [26].

Trabalhando com fornos de microondas é possível investigar o custo e o tempo de aquecimento da água através de um forno de microondas e comparar com o obtido por meio de um fogão à gás [111].

A criação de uma interface que permita ao computador compreender a linguagem do estudante, possibilitando uma abordagem qualitativa e criativa dos fenômenos físicos que propicie uma aprendizagem significativa para os alunos constitui um interessante tema de investigação, cujos resultados podem permitir a verificação da ocorrência de mudanças conceituais através da utilização de programas baseados na Inteligência Artificial [112].

Um estudo experimental sobre movimentos acelerados é proposto como meio de se obter interpretações qualitativas do conceito de aceleração, empregando-se uma análise gráfica dos resultados obtidos e promovendo-se discussões amplas entre o professor que conduz o experimento e o conjunto de alunos envolvidos [106].

Por sua vez, propondo um procedimento bastante interativo para o aprendizado de alguns conceitos de astronomia, encontra-se um artigo que utiliza um gnômon em um Jardim Astronômico para obter a altura do Sol, o meio-dia solar, os pontos cardeais e as estações do ano para qualquer latitude [102].

Através de exposições interativas, Axt e Bonadiman [107] utilizam diversos experimentos para desafiar o senso comum das pessoas e, deste modo, investigar como são suas interpretações e predições diante de experimentos contraintuitivos. Uma outra proposta semelhante utiliza laboratórios itinerantes como meio de levar estudantes e professores a ter contato com a produção e utilização de materiais didáticos, investigando-se as possíveis melhorias que o enfoque experimental pode trazer para as aulas de Física [42].

Procurando investigar os efeitos da microgravidade, no primeiro número do encarte Física na Escola da Revista Brasileira de Ensino de Física encontra-se um artigo que descreve os resultados obtidos em diversas experiências envolvendo diferentes tópicos de Física, com amplas discussões que permitiram um aprofundamento do aprendizado dos conceitos físicos envolvidos, a partir da grande participação dos estudantes [113]. No mesmo fascículo encontra-se um outro artigo onde se investiga de maneira interativa com alunos do ensino fundamental algumas propriedades de materiais magnéticos, possibilitando o aprendizado de conceitos básicos do magnetismo [114].

Utilizando voltímetros, Axt e Alves [115] sugerem uma estratégia de ensino que combina experimentação qualita- 
tiva e quantitativa associada com a realização de diversos testes-tarefa, onde os alunos devem fornecer previsões para as leituras de um voltímetro.

Por fim, merece destaque a organização de um amplo conjunto de experimentos de Física, de baixo custo e fácil realização, disponibilizados na internet de modo a auxiliar as atividades dos professores de Física [29].

\section{B.3.1 - Comentários e considerações}

Através do conjunto de propostas de atividades com natureza de investigação percebe-se que é possível alcançar uma vasta gama de diferentes objetivos educacionais, uma vez que estas atividades apresentam uma maior flexibilidade metodológica, quando contrastada com as atividades de demonstração e de verificação, embora seja possível, também para estas duas modalidades, o emprego de ações que enriqueçam a sua aplicação prática. Porém, no caso destas atividades o próprio caráter de investigação das mesmas pode ser considerado como um elemento facilitador para uma abordagem que seja centrada nos aspectos cognitivos do processo de ensino-aprendizagem, intrínsecos de uma metodologia que busca uma transformação mais profunda nos estudantes, seja ela vinculada aos aspectos conceituais, relacionados aos conteúdos de Física, ou mesmo comportamentais, como a capacidade de reflexão, abstração, generalização, síntese e de senso crítico.

\section{C - Utilização de novas tecnologias}

A utilização de novas tecnologias associadas à experimentação tem possibilitado o uso cada vez mais freqüente de computadores, uma vez que o emprego de tecnologias modernas está se tornando cada vez mais acessível nos meios educacionais. Diante disto, os computadores podem ser considerados como uma importante ferramenta de auxílio ao ensino de Física, apresentando imensas potencialidades de uso.

Uma análise bastante ampla das diferentes maneiras com que os computadores são empregados na área de Ensino é fornecida por Rosa [110], o qual analisa 182 trabalhos nacionais e internacionais produzidos entre 1979 e 1992 . Neste artigo, o autor destaca o uso de computadores como ferramenta de laboratório para controle de experimentos, na coleta e análise de dados experimentais, na simulação de fenômenos físicos e na instrução dirigida. Entretanto, cabe ressaltar que a grande maioria dos trabalhos analisados no artigo de Rosa não foram produzidos no Brasil, sendo que as poucas exceções não fazem parte das fontes pesquisadas para a elaboração deste trabalho.

Os poucos trabalhos encontrados descrevem o uso de computadores nos processos de coleta, geração e análise de dados experimentais [25, 69, 70, 71, 72, 103, 109], a partir de programas que permitem construir tabelas e elaborar gráficos. Nestes trabalhos os autores enfatizam a importância do uso de computadores em laboratórios como meio de aproximar os estudantes das tecnologias modernas, facilitando o desenvolvimento das atividades experimentais de modo a possibilitar aos alunos um maior tempo para a interpretação dos resultados [103], ainda que estes resultados permaneçam sujeitos a incertezas provenientes de fontes externas ao processo de digitalização [69]. Por outro lado, as facilidades provenientes do uso de computadores podem permitir aos estudantes repetir diversas vezes os experimentos e, assim, questionar os limites de validade dos modelos físicos utilizados e dos fatores e parâmetros envolvidos nos fenômenos abordados, contribuindo para o desenvolvimento do pensamento crítico e criativo [109], aproximando ainda os estudantes de uma ferramenta cada vez mais presente em seu cotidiano [73]. Outro fator destacado é que o uso de computadores pode permitir o estudo de situações difíceis ou inviáveis na prática, possibilitando ainda maior facilidade de compreensão dos fenômenos físicos [27].

Neste sentido, discute-se a possibilidade de utilização dos computadores em ambientes de ensino de modo a permitir uma aprendizagem significativa dos conteúdos ministrados, tomando-se por base uma analogia entre as teorias de aprendizagem e o desenvolvimento de linguagens de computação [112].

A utilização dos computadores pode auxiliar no estudo de temas de Física Moderna [59] e na abordagem de conceitos físicos através de processos que facilitem a aprendizagem e a reestruturação conceitual [26].

Portanto, de acordo com a maneira com que os computadores são utilizados é possível dispor de uma importante ferramenta capaz de criar condições que podem auxiliar no aprimoramento de diversas habilidades dos estudantes, como a sua capacidade crítica de interpretação e análise, a criatividade, a elaboração de hipóteses, entre outras, ao mesmo tempo em que os coloca em contato direto com instrumentos tecnológicos bastante atuais. Apesar destas características, que conferem significativa importância ao uso de computadores em atividades experimentais, constata-se que ainda há um pequeno número de pesquisadores e de publicações relacionadas com a utilização de computadores no ensino experimental de Física nas fontes pesquisadas, embora tenha sido constatado um significativo aumento de publicações no ano de 2001. Este fato indica que há poucos trabalhos sendo feitos e divulgados, constatandose, deste modo, ser necessário implementar-se o número de publicações nesta área a fim de facilitar o acesso daqueles que se interessam por essa modalidade de ensino.

\section{D - Relação com o Cotidiano}

Uma modalidade de uso da experimentação que pode despertar facilmente o interesse dos estudantes relaciona-se à ilustração e análise de fenômenos básicos presentes em situações típicas do cotidiano. Estas situações são consideradas como fundamentais para a formação das concepções espontâneas dos estudantes, uma vez que estas concepções se originariam a partir da interação do indivíduo com a realidade do mundo que os cerca. Esta linha de trabalho que explora aspectos físicos presentes em situações do cotidiano é defendida por alguns pesquisadores do Instituto de Física da USP que integram o Grupo de Reestruturação do Ensino de 
Física (GREF), com publicação de livros didáticos seguindo esta orientação. No que diz respeito a artigos publicados relacionados à experimentação, há trabalhos que exploram o uso de um simples gnômon para permitir a compreensão das estações do ano e outros aspectos relacionados com a Astronomia, como o meio-dia solar, os pontos cardeais e a altura do Sol [102]. Em outro trabalho, também baseado na astronomia básica, são fornecidas explicações para a existência e duração do dia e da noite e para as estações do ano [77]. Neste mesmo trabalho são dadas explicações para os eclipses e para as fases da Lua, empregando-se um material didático bastante simples, utilizando bolas de isopor e uma lâmpada. Há ainda um outro artigo que aborda questões relativas ao Sol, fornecendo uma abordagem quantitativa que procura verificar a potência irradiada pelo Sol, realizando um relacionamento desta grandeza com a energia que alcança a Terra e a mantém aquecida [51].

Abordando-se fenômenos e dispositivos relacionados com conceitos científicos elaborados e desenvolvidos ao longo do século passado, como por exemplo o efeito fotoelétrico, o laser e a emissão de corpo negro, é possível contribuir para que os estudantes compreendam alguns conceitos básicos da Física Moderna aplicados em diversas situações do cotidiano [44]. Assim, os estudantes passariam a entender como funciona o acionamento automático do sistema de iluminação pública e das portas de elevadores, as fibras óticas, a leitura do código de barras, o efeito estufa, entre outros [44]. Também explorando fenômenos da Física Moderna, o trabalho de Laburú [108] aborda elementos facilmente encontrados no cotidiano dos estudantes, como mostradores de cristais líquidos, presentes, por exemplo, em relógios digitais, calculadoras e joguinhos de bolso. Ao abordar a física envolvida nestes elementos, o autor destaca a possibilidade de criação de um ambiente estimulante para os alunos, motivando-os a compreender alguns conceitos e conhecimentos da Física Contemporânea, incluindo-se nesse caso a proposta de visualização de ondas eletromagnéticas estacionárias no interior de um forno de microondas [97]. Desse mesmo autor encontra-se um outro trabalho que se baseia no efeito estroboscópio decorrente da intermitência de fontes luminosas, associando este efeito com as observações rotineiras de rodas aparentemente girarem para trás ou darem a impressão de estarem paradas quando um veículo movimenta-se para frente, relatando ainda a manifestação deste efeito nas situações em que a mão é balançada com os dedos abertos na frente de telas de televisores ou computadores [60].

A produção de hologramas, cada vez mais freqüentes no dia a dia, a partir de um feixe de He-Ne também é um recurso didático que pode ser empregado, embora demande um custo um pouco maior [96], possibilitando aos alunos o conhecimento desta importante aplicação tecnológica relacionada com a área de Ótica.

Por sua vez, alguns efeitos visuais relacionados com a nitidez de imagens e a formação de sombra na retina são abordados utilizando-se anteparos com orifícios por Vuolo [116], enquanto um outro trabalho aborda a limitação do campo visual dos olhos [117]. Há ainda alguns artigos que abordam diferentes aspectos da visão humana, da estrutura do olho e dos defeitos de visão mais comuns [38], propondo atividades que permitem corrigir estes defeitos através do uso de lentes apropriadas [21]. O estudo da estrutura do olho através da dissecação de um olho de boi é o tema abordado em um interessante artigo [23] e, finalmente, observa-se uma proposta de realização de um curso que permite abordar aspectos da luz e da visão relacionados ao ensino de ótica geométrica, considerando-se as concepções espontâneas dos estudantes [24].

Por fim, há um outro exemplo de situação tipicamente encontrada no cotidiano de diversos alunos e que se relaciona ao uso de fornos de microondas para aquecimento de alimentos e substâncias líquidas. Explorando esta situação, Costa [111] realiza comparações entre o aquecimento da água obtido através de um forno de microondas e o obtido por meio de um fogão à gás, destacando o tempo e o custo de aquecimento nos dois processos.

\section{E - Construção de Equipamentos}

Nesta categoria foram classificados os artigos que apresentavam como ênfase temática a proposta de construção de determinados equipamentos, destinados ao uso em aulas práticas de Física. Embora correspondam aproximadamente a apenas $10 \%$ das publicações analisadas, considerou-se mais adequado enquadrá-los em uma categoria separada em função de suas características intrínsecas, uma vez que são voltados principalmente para o detalhamento da confecção dos equipamentos, encontrando-se ainda algumas sugestões de sua utilização.

Nesse sentido, na área de eletricidade é encontrado um trabalho que descreve a construção de um galvanômetro de imã móvel, base para a montagem de voltímetros e amperímetros. Esse projeto é considerado uma alternativa para os instrumentos comerciais, que apresentam normalmente um custo relativamente elevado, tendo o modelo proposto um suporte para o enrolamento dos fios feito em tubo de PVC [118].

Em trabalho posterior é realizada uma calibração do galvanômetro, de modo a transformá-lo em um voltímetro ou amperímetro, sendo analisada a precisão do instrumento em função da precisão dos componentes utilizados [119].

Na mesma área encontra-se a proposta de construção de um transformador com núcleo de ferro, que pode ser empregado em experiências que demandem correntes de baixa intensidade [120], e a construção de uma pilha eletroquímica [31].

Para aplicação em aulas de geometria e ótica geométrica são propostas a construção de um esferômetro e de um cilindrômetro, com materiais de baixo custo, cujo emprego em aulas práticas pode tornar as aulas mais interessantes, na medida em que permite um contato com situações reais [6].

Objetivando despertar a atenção e curiosidade dos alunos, motivando-os para o estudo dos temas da Astronomia, o trabalho de Canalle [95] propõe a construção de uma luneta feita a partir de lentes de óculos, que constitui um ins- 
trumento didático capaz de facilitar o aprendizado dos conceitos relacionados com esta área da Física.

$\mathrm{Na}$ área de ótica também são encontrados trabalhos que descrevem a construção de equipamentos que permitem a realização de diversas demonstrações de fenômenos óticos, como reflexão, refração, dispersão da luz, entre outros [39, 62], destacando-se a possibilidade de produção de redes de difração utilizando técnica fotográfica [30] e o entendimento do funcionamento do olho humano no processo de focalização das imagens [38].

A construção de um interferômetro de Michelson para observação de franjas de interferência é proposta em um contexto que aborda alguns aspectos históricos desse experimento [19].

Finalmente, na área de termologia observa-se uma pro- posta de construção de um calorímetro de baixo custo, que apresenta características técnicas melhores do que as verificadas nos calorímetros vendidos comercialmente [64].

\section{Análise quantitativa das publicações}

Analisando os artigos segundo as categorias discutidas anteriormente realizou-se uma distribuição dos trabalhos ao longo dos anos conforme expressam as tabelas fornecidas a seguir.

Tabela III - Ênfase Matemática X Ano de Publicação

\begin{tabular}{|c|c|c|c|c|c|c|c|c|c|c|c|c|}
\hline \hline Classificação & 1992 & 1993 & 1994 & 1995 & 1996 & 1997 & 1998 & 1999 & 2000 & 2001 & Total & $\%$ \\
\hline Qualitativo & 4 & 6 & 6 & 7 & 1 & 4 & 7 & 11 & 10 & 14 & 70 & 66 \\
Quantitativo & 0 & 3 & 3 & 4 & 2 & 2 & 3 & 8 & 3 & 8 & 36 & 34 \\
\hline Total & 4 & 9 & 9 & 11 & 3 & 6 & 10 & 19 & 13 & 22 & 106 & 100 \\
\hline \hline
\end{tabular}

A publicação de artigos baseados em atividades cuja ênfase encontra-se principalmente no enfoque dos aspetos qualitativos ocorreu em todos os anos do período abrangido por esta pesquisa, constituindo-se uma abordagem que merece destaque, uma vez que, além de corresponder a dois terços dos trabalhos publicados, algumas das atividades propostas e desenvolvidas permitem com maior facilidade enfatizar a importância dos conceitos espontâneos dos estudantes, além de possibilitar condições para que estes participem e intervenham intensamente nas atividades, refletindo e formulando hipóteses acerca dos fenômenos estudados. Outra característica importante desta modalidade, e que valoriza o expressivo número de artigos encontrados, é o fato destas atividades possibilitarem com facilidade uma abordagem de conceitos físicos utilizando o método investigativo. Neste método a participação ativa dos alunos é fundamental e propicia meios para o seu desenvolvimento cognitivo e para a ampliação da sua capacidade de observação e análise crítica das situações produzidas, gerando assim condições para que se processe uma reestruturação conceitual capaz de elevar o nível de aprendizagem dos alunos, fato que pode ser detectado, por exemplo, através da reformulação das explicações causais para os fenômenos estudados.

Em um segundo plano, apresentando um terço das publicações, encontram-se as atividades experimentais quantitativas, bastante empregadas e que permitem com maior facilidade o alcance de outros objetivos, como a verificação da validade das leis físicas e dos modelos teóricos, o tratamento estatístico dos dados obtidos, a análise da precisão das medidas, o aprendizado do manuseio de diversos instrumentos de medida, entre outros aspectos inerentes às atividades científicas, como a capacidade de análise e o senso crítico.

A tabela IV abaixo, fornece um quadro da produção de artigos classificados segundo o grau de direcionamento das atividades experimentais.

Tabela IV - Grau de Direcionamento X Ano de Publicação

\begin{tabular}{|c|c|c|c|c|c|c|c|c|c|c|c|c|}
\hline \hline Classificação & 1992 & 1993 & 1994 & 1995 & 1996 & 1997 & 1998 & 1999 & 2000 & 2001 & Total & $\%$ \\
\hline Investigação & 4 & 2 & 3 & 4 & 1 & 2 & 3 & 4 & 6 & 7 & 36 & 35,6 \\
Demonstração & 0 & 3 & 4 & 3 & 1 & 2 & 5 & 6 & 4 & 8 & 36 & 35,6 \\
Verificação & 0 & 1 & 2 & 3 & 1 & 2 & 2 & 8 & 3 & 7 & 29 & 28,8 \\
\hline Total & 4 & 6 & 9 & 10 & 3 & 6 & 10 & 18 & 13 & 22 & 101 & 100 \\
\hline \hline
\end{tabular}


Pode-se constatar da tabela acima que há um certo equilíbrio na distribuição das propostas quanto ao grau de direcionamento das atividades experimentais, embora o emprego de atividades com caráter de investigação e de demonstração predominem levemente em relação às atividades de verificação. Em relação às atividades de demonstração, que corresponde a $35,6 \%$ do total de artigos analisados, o seu expressivo emprego pode ser interpretado em parte possivelmente por se acreditar que tanto os autores dos artigos quanto os professores consideram que há uma maior facilidade de sua utilização em condições de aula, uma vez que normalmente demanda um menor tempo de preparo e execução, principalmente quando aplicada apenas como meio de se ilustrar um determinado fenômeno, visando facilitar o aprendizado do conceito abordado. Com exceção do ano de 1992, esta modalidade de experimentação esteve presente em todos os demais anos do período abor- dado nesta pesquisa, indicando tratar-se de uma modalidade bastante importante e que atrai a atenção e a dedicação de diversos autores.

No que se refere às atividades de natureza investigativa, foram observadas propostas em todos os anos pesquisados, sendo esta modalidade responsável por 35,6\% do total dos artigos.

Por fim, os artigos propondo atividades de verificação correspondem aproximadamente $29 \%$ do total e, da mesma forma que os artigos sobre atividades de demonstração, não foi observada nenhuma publicação no ano de 1992, ano em que foram verificados somente trabalhos de natureza investigativa.

Finalmente, a tabela $\mathrm{V}$ fornece um quadro da produção de artigos que envolvem a relação com o cotidiano, a construção de equipamentos e a utilização de novas tecnologias.

Tabela V - Cotidiano, Construção de Equipamentos e Novas Tecnologias X Ano de Publicação

\begin{tabular}{|c|c|c|c|c|c|c|c|c|c|c|c|c|}
\hline \hline Classificação & 1992 & 1993 & 1994 & 1995 & 1996 & 1997 & 1998 & 1999 & 2000 & 2001 & Total & $\%$ \\
\hline Cotidiano & 0 & 2 & 0 & 2 & 2 & 0 & 2 & 3 & 3 & 3 & 17 & 40 \\
Novas Tecnol. & 0 & 0 & 0 & 1 & 0 & 1 & 0 & 2 & 3 & 6 & 13 & 31 \\
Constr. Equip. & 0 & 3 & 1 & 0 & 1 & 0 & 1 & 1 & 2 & 3 & 12 & 29 \\
\hline Total & 0 & 5 & 1 & 3 & 3 & 1 & 3 & 6 & 8 & 12 & 42 & 100 \\
\hline \hline
\end{tabular}

Em relação aos artigos vinculados a outros aspectos metodológicos e que se encontram distribuídos na tabela $\mathrm{V}$, observa-se que há um número significativo de publicações que abordaram de alguma maneira elementos presentes ou relacionados com situações vivenciais típicas do cotidiano, embora essas publicações encontrem-se distribuídas de maneira bastante irregular ao longo dos anos, constatando-se uma certa estabilidade nos últimos quatro anos pesquisados.

A ênfase na construção de equipamentos, por sua vez, é abordada apenas em doze artigos, onde são encontradas diversas sugestões de possíveis aplicações didáticas dos equipamentos em aulas práticas.

Finalmente, a utilização de novas tecnologias, relacionadas com a área de informática, embora tenha se desenvolvido intensamente nos últimos anos, inclusive com diversos defensores de sua aplicação na área de educação, aparece nesta pesquisa representada por treze trabalhos enfocando o uso de computadores, sendo que dois deles analisavam as potencialidades em geral da utilização de computadores no ensino e os demais relatavam a sua efetiva aplicação em situação de ensino de Física. Assim, podemos considerar que foi relativamente pequeno o número de artigos abordando o uso de computadores como ferramenta para o ensino experimental de Física, uma vez que eles correspondem a apenas $12 \%$ do total de artigos analisados, apesar de ser cada vez maior a sua utilização na sociedade atual. Essa quantidade ainda pequena de trabalhos relatando o emprego de computadores no ensino de Física pode ser justi- ficada em parte pela necessidade de vultosos investimentos para que essa estratégia possa ser amplamente implantada nas escolas. Entretanto, acredita-se que com a crescente informatização das escolas verificada nos últimos anos, com a melhor capacitação dos professores e com o conseqüente aumento da demanda é possível que em um futuro próximo esta área passe a ser mais freqüentemente abordada, com a publicação de artigos que sugiram aplicações educacionais para os computadores ali instalados. Nesse sentido, um aumento de publicações já pode ser constatado no último ano dessa pesquisa, uma vez que foram encontrados seis artigos publicados em 2001, correspondendo a quase a metade de todos os artigos nessa área.

\section{Conclusões}

Nesse trabalho nosso objetivo principal foi promover uma análise da produção recente na área de investigações sobre o ensino de Física relacionadas à utilização da experimentação como estratégia de ensino e, desse modo, possibilitar uma melhor compreensão sobre as diferentes possibilidades e tendências dessas atividades tendo em vista subsidiar o trabalho de professores e pesquisadores do ensino no nível médio.

A análise dos dados que empreendemos tendo como referência os trabalhos publicados em revistas nacionais da área, considerando a década compreendida entre os anos de 1992 e 2001, revelou que essa temática consiste de um tema 
de grande interesse dos pesquisadores, seja pela expressiva quantidade de publicações, seja pela diversidade de enfoques abordados.

No que se refere ao grau de direcionamento das atividades, acredita-se que, de um modo geral, a utilização adequada de diferentes metodologias experimentais, tenham elas a natureza de demonstração, verificação ou investigação, pode possibilitar a formação de um ambiente propício ao aprendizado de diversos conceitos científicos sem que sejam desvalorizados ou desprezados os conceitos prévios dos estudantes. Assim, mesmo as atividades de caráter demonstrativo, amplamente utilizada pelos autores pesquisados e que visam principalmente a ilustração de diversos aspectos dos fenômenos estudados, podem contribuir para o aprendizado dos conceitos físicos abordados na medida em que essa modalidade pode ser empregada através de procedimentos que vão desde uma mera observação de fenômenos até a criação de situações que permitam uma participação mais ativa dos estudantes, incluindo a exploração dos seus conceitos alternativos de modo a haver maiores possibilidades de que venham a refletir e reestruturar esses conceitos [98]. Cabe ressaltar que grande parte das propostas analisadas baseiam-se na utilização de equipamentos e materiais de baixo custo e fácil aquisição, tornando acessível o seu emprego e adaptação mesmo em escolas que não disponham de laboratórios e recursos materiais significativos.

A criação de situações facilitadoras para o aprendizado pode ser caracterizada também pela possibilidade de se gerar conflitos cognitivos através da utilização de métodos dialógicos de ensino que privilegiam a "inclusão" dos estudantes no processo de aprendizagem. A adoção desses procedimentos favorece aos estudantes o desenvolvimento de sua capacidade de elaborar novos conhecimentos, conceitos e significados, o que pode ser entendido como uma restruturação conceitual. Para tanto, o emprego de metodologias mais eficientes de ensino de Física precisa ser considerado também no nível de formação de professores, procurando capacitá-los para uma nova prática pedagógica que os tornem mediadores do processo de desenvolvimento dos alunos, permitindo que elaborem situações que possibilitem aos seus alunos realizarem análises, reflexões e generalizações [1, 35, 41, 88]. Além desse aspecto, uma formação mais adequada dos professores pode ainda lhes permitir abordar com maior segurança conceitos inerentes à Física Moderna e Contemporânea [28, 73].

Por outro lado, considerando-se a ênfase matemática adotada nas atividades propostas, constata-se que a experimentação quantitativa permite alacançar importantes objetivos educacionais, destacando-se a possibilidade de comparação dos resultados obtidos com os valores previstos por modelos teóricos, verificando-se ainda os seus limites de validade. Essas atividades são propostas também para favorecer o entendimento do uso de instrumentos de medida, do tratamento estatístico dos dados, das fontes de erro, do tratamento gráfico, bem como outros aspectos típicos da investigação científica. No que se refere às propostas com ênfase nos aspectos qualitativos, pode-se destacar que a utilização de Laboratórios Não Estruturados (LNE) ou outras modalidades semelhantes, normalmente fundamentadas na utilização de questões abertas ou problematizadoras, permite criar situações que tendem a propiciar melhores condições para que os estudantes realizem testes de hipóteses e desenvolvam a criatividade e a sua capacidade de reflexão. Além disso, os experimentos qualitativos propiciam com maior facilidade condições para que o aluno possa contrastar os novos conhecimentos com os seus conceitos espontâneos. Nesse sentido, percebe-se que a preocupação principal dessa modalidade de experimentação é a de que as atividades propostas possam levar os estudantes a uma reformulação de suas explicações causais para os fenômenos investigados [13, 16, 17, 18, 26, 34, 98].

Analisando os demais aspectos relacionados aos trabalhos investigados constata-se que o uso de computadores em atividades experimentais apresenta um grande potencial em permitir que o estudante acesse tecnologias modernas, cada vez mais presentes em sua vida cotidiana, contribuindo-se desse modo para que ocorra a inclusão digital muito discutida e defendida atualmente [121]. Entretanto, para que o uso de computadores em ambiente escolar possa ser disseminado amplamente e de maneira eficiente, acredita-se ser necessário introduzir no processo de formação dos professores a utilização dos computadores, sendo essa uma forma de propiciar condições para que a atividade pedagógica docente incorpore diferentes interações e mediações no processo de educação em Física [122].

Por sua vez, os trabalhos que envolvem situações do cotidiano tendem a favorecer o aprendizado de conceitos novos na medida em que enfocam uma realidade vivida pelos estudantes e que são normalmente caracterizadas por situações nas quais os estudantes criam suas próprias concepções acerca de diversos fenômenos. Desse modo, acredita-se que atividades relacionadas com aspectos do cotidiano apresentam uma significativa importância, uma vez que os conceitos relacionados com os fenômenos abordados podem ser analisados segundo as conceituações científicas, permitindo aos alunos analisar e comparar a adequação e limitação das diferentes interpretações, contribuindo-se assim para que possam alcançar a desejada reestruturação conceitual.

Aliadas a essas atividades, os trabalhos que abordam conceitos inerentes à Física Moderna e Contemporânea propõem que os estudantes se aproximem do mundo tecnológico que os rodeia, permitindo-lhes compreender ao menos parcialmente algumas aplicações tecnológicas relacionadas com esses conceitos [28, 43, 44, 66, 68, 96, 97, $108]$.

De um modo geral, independente da linha ou modalidade adotada, constata-se que todos os autores são unânimes em defender o uso de atividades experimentais, podendo-se destacar dois aspectos fundamentais pelos quais eles acreditam na eficiência desta estratégia:

a) Capacidade de estimular a participação ativa dos estudantes, despertando sua curiosidade e interesse, favorecendo um efetivo envolvimento com sua aprendizagem. 
b) Tendência em propiciar a construção de um ambiente motivador, agradável, estimulante e rico em situações novas e desafiadoras que, quando bem empregadas, aumentam a probabilidade de que sejam elaborados conhecimentos e sejam desenvolvidas habilidades, atitudes e competências relacionadas ao fazer e entender a Ciência.

Além disso, os resultados dessa investigação reforçam que há uma ampla gama de possibilidades de uso das atividades experimentais no ensino médio, que vão desde as atividades de verificação de modelos teóricos e de demonstração, geralmente associadas a uma abordagem tradicional de ensino, até a presença já significativa de formas relacionadas a uma visão construtivista de ensino, representadas por atividades de observação e experimentação de natureza investigativa. Entretanto, para que os professores possam lograr sucesso em sua prática pedagógica, acredita-se ser um imperativo que a metodologia experimental adotada seja selecionada tendo em vista quais são os principais objetivos a serem alcançados com a mesma, uma vez que as diferentes modalidades de experimentação tendem a priorizar e facilitar o alcance de diferentes objetivos educacionais, cabendo portanto a quem conduzirá a atividade a escolha mais adequada da mesma, considerando o momento, o contexto e as finalidades pretendidas.

Esses resultados reafirmam posições já estabelecidas para o importante papel da experimentação no ensino de Física e sinalizam novas direções para sua utilização em sala de aula, revelando as atuais tendências das propostas formuladas pelos pesquisadores da área. Por outro lado, contatos freqüentes realizados com professores que estão desenvolvendo atividades docentes atualmente nos permite constatar que essas propostas ainda se encontram distantes dos trabalhos realizados em grande parte de nossas escolas, o que sem dúvida indica a necessidade de realização de novos estudos que visem melhorar as articulações e propiciar um aprofundamento das discussões dessa temática, buscando a efetiva implementação dessas propostas nos diversos ambientes escolares.

\section{Referências}

[1] Thomaz, M. F. (2000). "A experimentação e a formação de professores: uma reflexão”. Cad. Cat. Ens. Fís., 17 (3): 360369.

[2] Moraes, A. M. e Moraes, I. J. (2000). "A avaliação conceitual de força e movimento". Rev. Bras. Ens. Fís., 22 (2): 232-246.

[3] Diniz, R. E. S. (1996). "A pesquisa e o ensino de ciências: relato de uma experiência”. Série: Ciência \& Educação, $n^{\circ} 3$. UNESP, Baurú.

[4] Coelho, S. M.; Kohl, E.; Bernardo, S.; Wiehe, L. C.N. (2000). "Conceitos, atitudes de investigação e metodologia experimental como subsídio ao planejamento de objetivos e estratégias de ensino”. Cad. Cat. Ens. Fís., 17 (2):122-149.

[5] Alves Filho, J. P. (2000). "Regras da transposição didática aplicada ao laboratório didático". Cad. Cat. Ens. Fís., 17 (2): 174-188.
[6] Laburú, C. E.; Arruda, S. M. (1996a). "Considerações sobre a função do experimento no ensino de ciências". Série: Ciência $\&$ Educação, $n^{\circ}$ 3. UNESP, Baurú.

[7] Ventura, P. C. S. e Nascimento, S. S. (1992). "Laboratório Não Estruturado: uma abordagem do ensino experimental". Cad. Cat. Ens. Fís., 9 (1): 54-60.

[8] Arruda, S. M. e Villani, A. (1994). "Mudança conceitual no ensino de Ciências”. Cad. Cat. Ens. Fís., 11 (2): 88-99.

[9] Villani, A. (1989). "Idéias espontâneas e ensino de Física". Rev. Ens. Fís., 11: 130-147.

[10] Zylberstajn, A. (1983). "Concepções espontâneas em Física: exemplos em dinâmica e implicações para o ensino". Rev. Ens. Fís., 5 (2): 3-16.

[11] Abib, M. L. V. S. (1988). "Uma Abordagem Piagetiana para o Ensino de Flutuação dos Corpos", Textos Pesquisa Para o Ensino de Ciências, $\mathbf{n}^{o}$ 2, Editora da Faculdade de Educação da USP, São Paulo.

[12] Carvalho, A.M.P; Vannuchi, A.I.; Barros, M.A.; Gonçalvez, M.A.R; Rey, R.C (1998). "Ciências no Ensino Fundamental”, Escrituras Editora, São Paulo.

[13] Teixeira, S.K; Pacca, J. L. A. (1994). "O Peso Medido pela Balança: Ruptura e Continuidade na Construção do Conceito”, Cad. Cat. Ens. Fís., 11 (3): 154-171.

[14] Moreira, M. A; Axt, R. (1992). "O papel da Experimentação no Ensino de Ciências", Tópicos em Ensino de Ciência, São Paulo Distribuidora, São Paulo.

[15] Araújo, M. S. T.; Abib, M. L. V. S. (2000). "Experimentação no ensino médio: Novas possibilidades e tendências". in Caderno de Resumos do VII Encontro de Pesquisa em Ensino de Física, pág. 134-135 e CD-ROM, Florianópolis - SC, 27 a 31/03/2000.

[16] Barbosa, J. O.; Paulo, S. R.; Rinaldi, C. (1999). "Investigação do papel da experimentação na construção de conceitos em eletricidade no ensino médio”. Cad. Cat. Ens. Fís., 16 (1): 105-122.

[17] Villani, A. e Carvalho, L. O. (1993). "Representações mentais e Experimentos Qualitativos”. Rev. Bras. Ens. Fís., 15 (1-4): 74-89

[18] Villani, A. e Carvalho, L. O. (1994). "Dificuldades de um estudante na análise de Experimentos Qualitativos". Rev. Bras. Ens. Fís.,16 (1-4): 98-109

[19] Catelli, F. (2001). "Interferômetro de Michelson". Cad. Cat. Ens. Fís., 18 (1): 108-116.

[20] Silva Neto, J. N.; Canalle, J. B. G. (2001). "Magnetic force between parallel currents". Rev. Bras. Ens. Fís., 23 (1): 148150.

[21] Guedes, A. F.; Braun, L. F. M.; Rizzatti, M. R. (2001). "Visualizaç ão da miopia, da hipermetropia e do astigmatismo através do Simulador Didático do Globo Ocular". Rev. Bras. Ens. Fís., 23 (1): 53-56.

[22] Ferraz Netto, L. (2001). "Movimento do centro de massa". Física na Escola, 2 (2): 9.

[23] Saba, M. M. F. e Epiphanio, I. D. V. (2001). "Dissecando um olho de boi para entender a óptica do olho humano". Física na Escola, 2 (2): 16-18. 
[24] Gircoreano, J. P. (2001). "O ensino da óptica na perspectiva de compreender a luz e a visão". Cad. Cat. Ens. Fís.,18 (1): 26-40.

[25] Aguiar, C. E. e Laudares, F. A. (2001). "Aquisição de dados usando Logo e a porta de jogos do PC”. Rev. Bras. Ens. Fís., 23 (4): 371-380.

[26] Rezende, F. (2001). "Desenvolvimento e avaliação de um sistema hipermídia para facilitar a reestruturação conceitual em mecânica básica”. Cad. Cat. Ens. Fís., 18 (2): 197-213.

[27] Yamamoto, I. e Barbeta, V. B. (2001). "Simulções de experiências como ferramenta de demonstração virtual em aulas de teoria de Física”. Rev. Bras. Ens. Fís., 23 (2): 215-225.

[28] Ostermann, F. e Moreira, M. A. (2001). "Atualização do currículo de Física na escola de nível médio: um estudo desta problemática na perspectiva de uma experiência em sala de aula e da formação inicial de professores". Cad. Cat. Ens. Fís., 18 (2): 135-151.

[29] Quirino, W. G.; Lavarda, F. C. (2001). "Projeto 'Experimentos de Física para o ensino médio com materiais do dia-a-dia' ”. Cad. Cat. Ens. Fís.,18 (1): 108-116.

[30] Kalinowski, H. J.; Dümmer, O. S.; Giffhorn, E.; (2001). "Produção de redes de difração por técnica fotográfica no ensino médio". Cad. Cat. Ens. Fís., 18 (2): 248-254.

[31] Oliveira, A. G. M. I.; Oliveira, I. T. P. (2001). "Construção de uma pilha didática de baixo custo”. Cad. Cat. Ens. Fís., 18 (1): 101-107.

[32] Valadares, E. C. (2001). "Novas estratégias de divulgação científica e de revitalização do ensino de Ciências nas escolas". Física na Escola, 2 (2): 10-13.

[33] Cruz, G. K. (1997). "Uma nova visão para conduzir as atividades iniciais do laboratório de eletricidade". Rev. Bras. Ens. Fís., 19 (2): 282-286.

[34] Gonçalves, M. E e Carvalho, A. M. P. (1995). "As atividades de conhecimento físico: um exemplo relativo à sombra". Cad. Cat. Ens. Fís., 12 (1): 7-16.

[35] Castro, R. S. e Cerqueira, F. E. (1992). "Atividades experimentais: canal de interlocução com professores em treinamento". Rev. Bras. Ens.Fís.,14 (4): 205-208.

[36] Ribeiro, M. S.; Freitas, D. S.; Miranda, D. E. (1997). "A problemática do ensino de laboratório de Física na UEFS". Rev. Bras. Ens. Fís., 19 (4): 444-447.

[37] Mizukami, M., G. N. (1986). “Ensino: as abordagens do processo”. Editora Pedagógica e Universitária Ltda., São Paulo.

[38] Guedes, A. F.; Braun, L. F. M.; Rizzatti, M. R. (2000). "Simulador didático do cristalino ocular". Rev. Bras. Ens. Fís., 22 (1): 137-139.

[39] Vuolo, J. H. e Furukawa, C. H. (1999). "Modelos de componentes óticos em resina". Rev. Bras. Ens. Fís., 21 (2): 280288.

[40] Barreiro, A.C.M. e Bagnato, V. (1992). "Aulas demonstrativas nos cursos básicos de Física”. Cad. Cat. Ens. Fís., 9 (3): 238-244.

[41] Heineck, R. (1999). "O ensino de Física na escola e a formação de professores: Reflexões e Alternativas". Cad. Cat. Ens. Fís., 16 (2): 226-241.
[42] Macedo, Z. S.; Andrade, M. F.; Santos, C. P.; Moreira, M. L.; Nascimento, P. V.; Monteiro, O. P.; Valerio, M. E. G. (2000). "Ciência em foco: um laboratório itinerante de Física". Rev. Bras. Ens. Fís., 22 (1): 140-142.

[43] Cavalcante, M. A.; Jardim, V.; Barros, J. A. A. (1999b). "Inserção de Física Moderna no ensino médio: difração de um feixe laser”. Cad. Cat. Ens. Fís., 16 (2): 154-169.

[44] Valadares, E. C. e Moreira, A. M. (1998). "Ensinando Física Moderna no segundo grau: Efeito fotoelétrico, laser e emissão de corpo negro". Cad. Cat. Ens. Fís., 15 (2): 121135.

[45] Marques, P. M. A.; Barreiro, A. C. M.; Souza, A.; Galeano, E. (1994). "Demonstração em teoria cinética". Cad. Cat. Ens. Fís., 11 (2): 100-104.

[46] Pimentel, J. R. (1998). "A tesoura de Gauss - uma tesoura para cortar linhas de campo magnético". Cad. Cat. Ens. Fís., 15 (1): 82-86.

[47] Almeida, L. D. e Vaniel, B. V. (1995). "Experimentos de equil'1 brio: sistemas de forças e polias". Cad. Cat. Ens. Fís., 12 (2):134-141.

[48] Chernikoff, R. E.; Rúbio, L. A.; Cáceres, R. E.; Rodríguez, O. J. (2001). "Sencillo dispositivo para determinar la posición del centro de masa de um sistema". Cad. Cat. Ens. Fís., 18 (1): 52-55.

[49] Dornelles Filho, A. A. (1996). "Uma questão em hidrodinâmica”. Cad. Cat. Ens. Fís., 13 (1): 76-79.

[50] Arriassecq, I.; Lester, M.; Stipich, S. (1999). "Cuerpo rigido: Experiencia de laboratorio con material de bajo costo". Cad. Cat. Ens. Fís., 16 (1): 92-100.

[51] Perottoni, C. A. e Zorzi, J. E. (1993). "Determinação da constante solar por meio de um 'calorímetro' com gelo". Cad. Cat. Ens. Fís., 10 (2): 173-178.

[52] Pintão, C. A. F.; Souza Filho, M. P.; Grandini, C. R. (2001). "Medida do momento de inércia de um disco". Rev. Bras. Ens. Fís., 23 (1): 48-52.

[53] Chernikoff, R. E.; Rúbio, L. A.; Cáceres, R. E.; Rodríguez, O. J. (1999). "Una sencilla experiencia para estudar la Ley de Boyle”. Cad. Cat. Ens. Fís., 16 (2): 176-179.

[54] Laburú, C. E. e Almeida, C. J.. (1998a). "Lei de Hooke: uma comparação entre sistemas lineares”. Cad. Cat. Ens. Fís., 15 (1): 71-81.

[55] Amaku, M.; Moralles, M.; Horodynski-Matsushigue, L. B.; Pacholati, P. R. (2001). "Fractais no laboratório didático". Rev. Bras. Ens. Fís., 23 (4): 422-428.

[56] Oliveira, J.; Panzera, A. C.; Gomes, A. E. Q.; Tavares, L. (1998). "Medição de tempo de reação como fator de motivação e de aprendizagem significativa no laboratório de Física”. Cad. Cat. Ens. Fís., 15 (3): 301-307.

[57] Lopes, E. M. e Laburú, C. E. (2001). "Diâmetro de um fio de cabelo por difração (um experimento simples)". Cad. Cat. Ens. Fís., 18 (2): 240-247.

[58] Laburú, C. E. e Ferreira, N. C. (1996b). "Construindo um esferômetro e cilindrômetro (equipamentos de baixo custo)". Cad. Cat. Ens. Fís., 13 (2): 165-171.

[59] Cavalcante, M. A. ; Piffer, A.; Nakamura, P. (2001). "O uso da Internet na compreensão de temas de Física Moderna para o ensino médio". Rev. Bras. Ens. Fís., 23 (1): 108-112. 
[60] Laburú, C. E.; Silva, O. H. M. (1999). "Medindo a frequiência da rede elétrica por efeito estroboscópio: com um equipamento mecânico simples". Cad. Cat. Ens. Fís., 16 (3): 332339.

[61] Simões Filho, M. (1995). "Fórmula 1 \& Física 1"; Rev. Bras. Ens. Fís., 17 (3): 255-260.

[62] Viscovini, R. C. (2000). "Kit de experimentos ópticos com apontador laser”. Rev. Bras. Ens. Fís., 22 (1): 143-145.

[63] Bagnato, L. V.; Muniz, S. R.; Bagnato, V. S. (1995). "Verificação experimental da lei dos gases usando um balão de borracha submerso". Rev. Bras. Ens. Fís.,17 (1):104-106

[64] Laburú, C. E.; Rodrigues, R. (1998c). "Calorímetro de baixo custo”. Cad. Cat. Ens. Fís., 15 (3): 319-322.

[65] Bagnato, V. S. (1994). "O análogo mecânico da Lei de Ohm”. Rev. Bras. Ens. Fís., 16 (1-4): 129-131.

[66] Catelli, F. (1999a). "Projeção de espectros com um CD e retroprojetor”. Cad. Cat. Ens. Fís., 16 (1): 123-126.

[67] Cavalcante, M. A.; di Benedetto, A. (1999c). "Instrumentação em Física Moderna para o ensino médio: uma nova técnica para a análise quantitativa de espectros". Rev. Bras. Ens. Fís., 21 (3): 437-446.

[68] Garcia, N. M. e Kalinowski, H. J. (1994). "Um espectroscópio simples para uso individual”. Cad. Cat. Ens. Fís.,11 (2): 134-140.

[69] Cavalcante, M. A. e Tavoralo, C. R. C. (2000a). "Cuidados na utilização de sistemas de aquisição de dados no ensino de Física”. Rev. Bras. Ens. Fís., 22 (2): 247-258.

[70] Cavalcante, M. A. e Tavoralo, C. R. C. (2000c). "Projete você mesmo experimentos assistidos por computador: construindo sensores e analisando dados”. Rev. Bras. Ens. Fís., 22 (3): 421-425.

[71] Haag, R. (2001). "Utilizando a placa de som do micro PC no laboratório didático de Física”. Rev. Bras. Ens. Fís., 23 (2): 176-183.

[72] Montarroyos, E.; Magno, W. C. (2001). "Aquisição de dados com a placa de som do computador”. Rev. Bras. Ens. Fís., 23 (1): 57-62.

[73] Cavalcante, M. A. (1999d). "O ensino de uma NOVA FÍSICA e o exercício da cidadania”. Rev. Bras. Ens. Fís., 21 (4): 550551.

[74] Axt, R. (1993). "Ondas estacionárias longitudinais em uma barra metálica”. Cad. Cat. Ens. Fís., 10 (1): 93-94.

[75] Canalle, J. B. G. e Oliveira, I. A. G. (1994a). "Comparação entre os tamanhos dos planetas e do Sol". Cad. Cat. Ens. Fís., 11 (3): 212-220.

[76] Canalle, J. B. G. e Moura, R. (1997). "A Lei de Faraday e a de Lenz”. Cad. Cat. Ens. Fís., 14 (3): 299-301.

[77] Canalle, J. B. G. (1999b). "Explicando astronomia básica com uma bola de isopor". Caderno Cat. Ens. Fís., 16 (3): 314-331.

[78] Canalle, J. B. G. e Moura, R. (2000). "Freio magnético". Cad. Cat. Ens. Fís., 17 (1): 96-100.

[79] Misoguti, L.; Mendonça, C. R.; Tuboy, A. M.; Habesch, R.; Bagnato, V. S. (1997). "Lentes esféricas: uma demonstração para alunos do segundo grau”. Rev. Bras. Ens. Fís., 19 (4): 448-450.
[80] Silveira, F. S. (1995). "Sem quebrar as taças". Cad. Cat. Ens. Fís., 12 (2): 152-156.

[81] Mendonça, C. R.; Misoguti, L.; Muniz, S. R.; Tuboy, A. M.; Bagnato, V. S. (1998). "Demonstrações de reflexão total interna para alunos do segundo grau". Rev. Bras. Ens. Fís., 20 (3): 296-300.

[82] Pimentel, J. R. (1999). "Lentes biconvexas convergentes e divergentes”. Cad. Cat. Ens. Fís., 16 (3): 344-348.

[83] Canalle, J. B. G. e Moura, R. (1998a). "Forças entre condutores paralelos de correntes contínuas”. Cad. Cat. Ens. Fís., 15 (2): 206-209.

[84] Hessel, R. (1999).“A lei de Faraday e a lei de Lenz”. Cad. Cat. Ens. Fís, 16 (3):340-343.

[85] Catelli, F. (1999b). "Correntes induzidas". Cad. Cat. Ens. Fís., 16 (3): 344-348.

[86] Dionísio, P. H.; Heinemann, C.; Becker, R. E.; Spielmann, R. D. (1999). "Força eletromotriz devida ao movimento". Cad. Cat. Ens. Fís., 16 (2): 246-248.

[87] Catelli, F. e Pezzini, S. (2001). "A água não derrama ...". Física na Escola, 2 (2): 18.

[88] Figueroa, D. e Gutierrez, G. (1992). "Demonstraciones de Física: Elemento motivador en la formación del docente". Rev. Bras. Ens. Fís., 14 (4): 253-256.

[89] Canalle, J. B. G. e Moura, R. (1998b). "Duplo cone, quádrupla finalidade”. Cad. Cat. Ens. Fís., 15 (3): 323-327.

[90] Pimentel, J. R. (1995). "O princípio da inércia usando um disco flutuador”. Cad. Cat. Ens. Fís., 12 (2): 150-151.

[91] Braun, L. F. M; Braun, T. (1994). "A montagem de Young no estudo da interferência, difração e coerência de fontes luminosas”. Cad. Cat. Ens. Fís., 11 (3): 184-195.

[92] Galli, C. e Salami, M. A. (1999), "Laboratório caseiro: registros de figuras de difração da luz em papel fotográfico”. Cad. Cat. Ens. Fís., 16 (2): 242-245.

[93] Piubéli, U. G. e Piubéli, S. L. (1995). "Fonte de Heron". Cad. Cat. Ens. Fís., 12 (1): 47-52.

[94] Dias, P. M. C.; Morégula, A. A.; Thompson, C. P.; Tavares, L. M. B.; Gabcan, L.; (1993). "Um presente de grego: a máquina de Hero de Alexandria”. Cad. Cat. Ens. Fís., 10 (2): 148-156.

[95] Canalle, J. B. G. (1994b). "A luneta com lente de óculos". Caderno Cat. Ens. Fís., 11 (2): 141-144.

[96] Galli, C. (1993). "Produção de hologramas com equipamentos de baixo custo". Cad. Cat. Ens. Fís., 10 (3): 258-261.

[97] Laburú, C. E.; Ota, M. I. N.; Basso, R. L. O.; Almeida, C. J. (2000). "Visualizando ondas eletromagnéticas estacionárias (um experimento na cozinha de casa)". Cad. Cat. Ens. Fís., 17 (3): 328-335.

[98] Carvalho, A. M. P.; Santos, E. I.; Santos, M. C. P. S.; Date, M. P. S.; Fujii, S. R. S.; Nascimento, V. B. (1999). "Termodinâmica - um ensino por investigação", Editora da Faculdade de Educação da USP, São Paulo.

[99] Bagnato, V.S. e Marcassa, L.G.(1997). "Demonstrações da inércia através do bloco suspenso". Revista Bras. Ens. Fís.,19 (3): 364- 366. 
[100] Dornelles Filho, A. A. (1998). "Uma representação do fenômeno da interferência de ondas utilizando lâminas transparentes e retroprojetor". Caderno Cat. Ensino Fís., 15 (1): 87-93.

[101] Canalle, J. B. G. (1999a). "O furo da lata d'água”. Cad. Cat. Ens. Fís., 16 (1): 101-104.

[102] Afonso, G. B. (1996)."Experiências simples com o gnômon”. Rev. Bras. Ens. Fís., 18 (3): 149-154.

[103] Cavalcante, M. A.; Tavoralo, C. R. C. (1997). "Estudo do lançamento horizontal utilizando o computador para aquisição e análise de dados”. Cad. Cat. Ens. Fís., 14 (3): 276-287.

[104] Guimarães, L. A. (1993). "Um motor de corrente contínua". Cad. Cat. Ens. Fís.,10 (2): 185-187.

[105] Moura, R. e Canalle, J. B. G. (1999). "Quebra-se um imã, faz-se um cientista”. Cad. Cat. Ens. Fís., 16 (2): 249-253.

[106] Laburú, C. E. (1995). "Movimentos acelerados: um experimento de baixo custo para o 20 grau". Cad. Cat. Ens. Fís., 12 (1):53-55.

[107] Axt, T.; Bonadiman, H.; Silva, M. T. X. (2000). "Um experimento contraintuitivo”. Cad. Cat. Ens. Fís., 17 (1): 27-32.

[108] Laburú, C. E.; Simões, A. M., Urbano, A. A. (1998b). "Mexendo com polaróides e mostradores de cristais líquidos $(O$ ensino da Física Contemporânea, tendo como pano de fundo a Física do cotidiano)". Cad. Cat. Ens. Fís., 15 (2): 192-205.

[109] Cavalcante, M. A.; Tavoralo, C. R. C.; Caetano, A. S. C., Silva, E. (1999a). "Proposta de um laboratório didático em microescala assistido por computador para estudo de mecânica”. Rev. Bras. Ens. Fís., 21 (1): 127-135.

[110] Rosa, P. R. S. (1995). "O uso de computadores no ensino de Física. Parte I: Potencialidades e uso real”. Rev. Bras. Ens. Fís., 17 (2): 182-195.

[111] Costa, I. F. (1995). "Fogo versus microondas". Rev. Bras. Ens. Fís., 17 (2): 180-181.
[112] Nogueira, J. S.; Rinaldi, C.; Ferreira, J. M.; de Paulo, S. R. (2000). "Utilização do computador como instrumento de ensino: uma perspectiva de aprendizagem significativa". Rev. Bras. Ens. Fís., 22 (4): 517-522.

[113] Saba, M. M. F. (2000). "Microgravidade na sala de aula". A Física na Escola, 1 (1): 15-17.

[114] Cavalcante, M. A. (2000b). "Magnetismo para crianças". A Física na Escola, 1 (1): 21-24.

[115] Axt, R. e Alves, V. M. (1994). "O papel do voltímetro na aquisição do conceito de diferença de potencial”. Cad. Cat. Ens. Fís., 11 (1): 19-26.

[116] Vuolo, J. H. (1996). "Efeitos visuais com orifícios". Rev. Bras. Ens. Fís., 18 (3): 191-193.

[117] Salinas, J. e Sandoval, J. (2000). "Enseñanza experimental de la óptica geométrica: campos de visión de lentes y espejos”. Rev. Bras. Ens. Fís., 22 (2): 259-265.

[118] Arribas, S. D. (1993a). "Galvanômetro". Cad. Cat. Ens. Fís., 10 (1): 88-92.

[119] Paz, A. M. e Alves Filho, J. P. (1993). "Galvanômetro-2. Voltímetro-Amperímetro”. Cad. Cat. Ens. Fís., 10 (2): 179184.

[120] Arribas, S. D. (1993b). "Transformador". Cad. Cat. Ens. Fís., 10 (3): 269-276.

[121] Reis, E. M.; Linhares, M. P.; Rapkiewicz, C. E. “Integrando ações de inclusão digital e tecnológica: uma digressão na formação inicial e continuada de professores de Física no norte fluminense". in Caderno de Resumos do XV Simpósio Nacional de Ensino de Física, pág. 160, Curitiba - PR, 21 a 26/03/2003.

[122] Brizzi, M. L. S. “A educação em Física mediada pelo computador". in Caderno de Resumos do XV Simpósio Nacional de Ensino de Física, pág. 155, Curitiba - PR, 21 a 26/03/2003. 